\title{
LA BIBLIOTECA DE AGUSTÍN PABLO DE ORDEÑANA ${ }^{1}$
}

\author{
Cristina González Caizán ${ }^{2}$
}

\section{agustín Pablo de Ordeñana. La hechura del Marqués de la Ensenada}

Agustín Pablo de Ordeñana y Goyenechea (1711-1765) fue amigo y principal hechura del Marqués de la Ensenada. Poco sabemos todavía de este personaje ya que siempre estuvo a la sombra del marqués formando parte de su clientela personal junto con otras hechuras y fidelidades como José Banfi, Alonso Pérez Delgado, el abate Facundo Mogrovejo, Ignacio de Orcasitas, José Francia, Bartolomé Valencia, Pedro Gordillo, Jorge Juan, Antonio de Ulloa, el abate Gándara, Juan Fernandez de Isla, el Padre Rávago o la marquesa de Torrecilla.A ellos habría que sumar el animoso, optimista y divertido padre Isla, devoto de Don Zenón.

Ordeñana nació en Bilbao en el seno de una acaudalada familia vizcaina. Desciende de cuatro casas solares infanzonas, como consta en el expediente formulado cuando accedió a la orden de Calatrava ${ }^{3}$. Su padre, Don Miguel de Ordeñana, fue regidor capitular de la villa de Bilbao en 1713. Sus abuelos, tanto el paterno como el materno, también fueron fieles regidores de esta villa; su abuelo paterno fue además mayordomo de la Iglesia de San Miguel de Basauri. Es el segundo de tres hermanos, Don Jose Antonio y Don Pedro Antonio. El primero fue canónigo en Toledo; el tercero de los hermanos, Don Pedro Antonio, fue Comisario Real de Guerra y Marina con seguridad antes de 1753 . Tuvieron también dos hermanas menores más Doña María Tomasa y Doña María Josefa.

La primera referencia que tenemos de Ordeñana es de 1741, cuando es elegido para acompañar a Italia a Don Felipe como oficial mayor de la Secretaría de Estado del Infante, cuya titularidad regentaba el Marqués de la Ensenada que también lo era de la Secretaría de Guerra desde 1740; pero podemos aventurar, casi con toda seguridad, que en

1. Este trabajo se inscribe en el proyecto DGYCIT PB 95-0698 "El tiempo de Ensenada", dirigido por J.L. Gómez Urdáñez, al que la Universidad de La Rioja ha concedido también una Ayuda a la investigación para el grupo del que forma parte la autora.

2. Universidad de La Rioja.

3. AHN, OOMM, Expedientillo, leg. 12070. 
1737 Ordeñana se encontraba ya desempeñando el papel de secretario y hombre de confianza de Ensenada en el Almirantazgo. Hemos encontrado una carpetilla de minutas de este Almirantazgo donde el Infante que es Almirante General propone a Ordeñana como Comisario de Marina ${ }^{4}$ y dice estar ejerciendo ya ese cargo. Por lo tanto Ordeñana toma ya contacto con la marina y el mundo del Marqués de la Ensenada a la temprana edad de 26 años (también el patrón es muy joven entonces, 35 años).

En abril de 1743, cuando Ensenada parte apresuradamente de Chamberi para ocupar sus cuatro secretarías, deja en su lugar a Ordeñana. De abril a octubre, el joven Agustín toma contacto directamente y sin intermediarios con el mundo diplomático correspondiente del Infante, con su corte y con la de Madrid. Habla en francés, conoce a personajes de peso en la corte de Luis XV, tiene relaciones intensas a raíz de la guerra y la siempre dificil de mantener alianza hispano-francesa. Sin duda, a diferencia del mundo cortesano español del interior, con escasas relaciones con el mundo internacional, Ordeñana y Ensenada tuvieron estos años el privilegio de ver otras realidades desde el exterior, lo que se reflejará en su gusto afrancesado, en sus planteamientos políticos y, en fin, en su acervo cultural. De regreso a España Ordeñana fue nombrado en ese mismo año de 1743 Consejero del Consejo de Hacienda "en atención a sus méritos y servicios en dicha secretaría"; en 1744 fue ordenado por el Rey Caballero de la Orden de Calatrava ${ }^{6}$; en 1751, Secretario de Estado y Guerra con asiento de voto y consejero por muerte del Marqués de Uztariz ${ }^{7}$, a la vez que se le relevaba de su plaza de Consejero de Hacienda y, en fin, en 1754 tuvo a su cargo la dirección de las obras del Real Palacio ${ }^{8}$.

Ordeñana estuvo siempre tras las decisiones del marqués en los grandes problemas políticos: el Concordato de 1753, la abolición de las rentas provinciales, el Real Giro (el primer Banco de España para pagos en el extranjero), los proyectos bélicos incluyendo el rearme naval. Cuando el 20 de Julio de 1754 caiga el Marqués de la Ensenada uno de los primeros en seguirle será Ordeñana. Las sátiras políticas recogidas por Teófanes Egido nos muestran hasta qué punto la dicha y la desdicha de ambos estuvieron unidas:

\footnotetext{
Juntamente el rey ordena que en esta misma mañana el Abate y Ordeñana padezcan la misma pena; es una sentencia buena que corran igual fortuna, y enviarlos sin duda alguna todos a diversa parte, es porque iban con mucho arte todos tres antes a una.?
}
4. AHN, Estado, leg. 3224.
5. AHN, Estado, leg. 6400.
6. AHN, OOMM, leg. 12070.
7. AHN, Estado, leg. 2812.
8. AHN, Estado, leg. 2604.
9. EGIDO,T. 1973, p. 238. 
El Marqués fue desterrado a Granada, Facundo Mogrovejo a Burgos y Ordeñana a Valladolid. Banfi, Orcasitas y otros ensenadistas exonerados no salieron de Madrid. Los desterrados tenían que presentarse a las respectivas autoridades: Ordeñana a José de Las Infantas, presidente de la Chancillería de Valladolid; éste le vigilaría la correspondencia que le llegase permitiéndole sólo la relación epistolar con su familia. Pero esto fue difícil de cumplir, más si cabe porque en esa ciudad vivía un primo jesuita del desterrado que le debía pasar las cartas sin dificultad, como notaba el propio José de las Infantas que en carta a Ricardo Wall le decía ${ }^{10}$ :

"en cuanto a su correspondencia por escrito siempre es más difícil la averiguación pudiéndole valer de segunda mano y de tercera, sin que se vea letra ni carta suya, especialmente teniendo como tiene en esta ciudad un bermano jesuita cuya confianza puede facilitarle lo que le apetezca en este punto."

JOSÉ DE LAS INFANTAS a WALL.Valladolid, 3 agosto de 1754.

La caida de Ensenada y sus hechuras han sido estudiadas recientemente por Gómez Urdánez ${ }^{11}$. En una posterior investigación acometeremos el gran problema historiográfico que plantea la responsabilidad de Ordeñana en la caída de Ensenada. Se ha sospechado siempre que Ensenada, una vez muerto Carvajal, pudo pensar en dominar de foma total los escenarios de poder en la corte de Fernando VI interviniendo a favor de Ordeñana en la sucesión del secretario de Estado, pero Gómez Urdáñez sospecha que es posible que el marqués, pragmático como siempre, se diera cuenta mejor que nadie de que ascender a Ordeñana era crispar aún más a un Huéscar completamente entregado a la conjura contra él desde antes de morir Carvajal ${ }^{12}$. Como es sabido, Fernando VI se inclinó por Ricardo Wall para Estado -tras un tormentoso interinato de Huéscar-. Ensenada y Ordeñana conocían perfectamente -como toda la corte- "la tormenta que se fraguaba": para que estallara solo hizo falta que Huescar y Wall recibieran el apoyo -bien que indirecto, como ha demostrado Gómez Urdáñez- del embajador inglés Keene, pero vía embajada de España en Londres.

Ordeñana sale a la luz pública tras su caída, la sátira popular se ensaña con el equipo de Ensenada lo mismo que con él, como ha recogido Teófanes Egido. Se le acusa de abusar de la confianza de sus jefes, de impotencia para atender todos los problemas, de labrarse una fortuna más modesta que Ensenada pero de origen igualmente inconfesable aunque fácil de presumir ${ }^{13}$. Esta es una crítica fácil de explotar, el Rey no es malo, son los consejeros los que abusan de su bondad, se enriquecen ilícitamente y abusan de su poder ${ }^{14}$.Antonio Rodriguez Villa le define como un personaje con gran celo, interés e inteligencia presto siempre al servio público y el bienestar de España, cuenta cómo todos los cargos que se le pudieron hacer eran falsos y cómo no se merecía el trato que le dieron. Según nos cuenta el archivero decimonónico, el mejor biografiador de Ensenada, Ordeñana poco después de ser depuesto de su empleo se vio en la necesidad de vender los muebles de su casa para pagar la deudas que había contraído en Madrid para mantenerse con decencia ${ }^{15}$.

10. AHN, Estado, leg. 5048.

11. GÓMEZ URDÁÑEZ, J.L. 1996.

12. GÓMEZ URDÁÑEZ, J.L., "El embajador Duras en la corte española", Hispania, en prensa.

13. EGIDO,T. 1971, p. 214.

14. LORENZO CADARSO, P.L. Y GÓMEZ URDÁÑEZ, J.L. 1993.

15. RODRÍGUEZ VILLA, A. 1878, p. 279. 
En abril de 1760 Carlos III le devolvió su libertad, igual que al Marqués y al resto de los ensenadistas. El 27 de mayo de 1760 legó Ordeñana desde Valladolid y todos se juntaron en casa de Don José Banfi que estuvo siempre en Madrid, a excepción de Mogrovejo que ya había muerto. Una copia del capítulo de la Gaceta de Madrid de 20 de mayo de 1760 decía lo siguiente:

"Atendiendo el Rey a los méritos de Don Agustín Pablo de Ordeñana y no habiendo hallado causa para el destierro que ha estado sufriendo en Valladolid, se ha dignado levantárselo y concederle libertad de que pueda residir en cualquier paraje de estos reinos, sin excepción de la Corte"16.

El 1 de mayo de 1761 se le concedió una plaza de Consejero del Consejo de Guerra y en 1765, año de su muerte, se le concedía la Intendencia de la ciudad de Madrid. Un acérrimo ensenadista como el Padre Isla acogía así de entusiasmado este nuevo cargo de Ordeñana y decía alegrarse de ello:

"por cuatrocientos motivos, y espero darle la enborabuena cuando se posesione de ella. Este empleo, tan justa y oportunamente conferido, acredita que todavía vive nuestro Gran Marqués; Ojalá fuera tan plenamente como lo suspira toda la monarquía"1.

Ordeñana formó parte de esas "hechuras cenonicias" como las calificó Rafael Olaechea ${ }^{18}$ siendo la más perfecta de todas ellas.Al igual que toda la primera mitad del siglo XVIII, el Reinado de Fernando VI y el equipo ministerial del Marqués de la Ensenada han estado abandonados por la casi totalidad de los modernistas en favor de la segunda mitad y del reinado eclipsador de Carlos III hasta el magnífico estudio de Gómez Urdañez sobre el primer equipo ministerial del tercer borbón. Pero el marqués no estaba sólo y se apoyaba en un importante numero de fidelidades, una de ellas y quizá la más importante fue Ordeñana. Quizá, la creación de una red de gente fiel, de extracción poco brillante pero eficaz, hombres entregados al trabajo de administrar el país, ${ }^{19}$ es la característica que define el gobierno de Ensenada y le diferencia más del de los grandes déspotas del XVIII español.

De momento conocemos poco el alcance político de Ordeñana en la política de Fernando VI, lo que sí conocemos es una impresionante biblioteca -la que se inventarió por orden de Wall el día de su caída- que demuestra la vasta cultura cosmopolita de su dueño en un momento en que España comienza a dar los primeros pasos de la Ilustración, una Ilustración no tan apocada como se ha querido ver. ${ }^{20}$ De las inquietudes y de la altura intelectual de Ordeñana da cuenta una interesante correspondencia que mantuvo con Feijoo, que publicaremos en el próximo número de esta revista. Como veremos la biblioteca de Ordeñana es espectacular y demuestra que es el brazo "ilustrado" de Ensenada, el hombre que estaba al corriente de todo lo que se producía en Europa. Conocía varias lenguas y muestra interés por aprender otras como el

16. BN. Mss. 3790.

17. OLAECHEA, R. 1981, p. 197.

18. Ibídem.

19. FERNÁNDEZ ALBADALEJO, P. 1988. Tomo I.

20. Una obra reciente refleja bien este cosmopolitismo español de mediados de siglo: cfr. SÁNCHEZ BALCO-PARODY, F. 1991. 
inglés, de moda ya por aquellos años y tiene una gran aficción a la literatura. Como adelanto, podíamos decir que Ensenada se orientaba más a los saberes técnicos y Ordeñana a los de contenido ideológico, literario y, en general, humanístico.

Además de analizar esta espléndida biblioteca de más de 1.500 volúmenes, la compararemos con la del Marqués de la Ensenada, estudiada por Gómez Urdáñez, y con la de Campomanes, cuyo inventario fue realizado entre 1840-1842, estudiada por J. Soubeyroux ${ }^{21}$.

\section{EL estudio de una biblioteca. Problemas metodológicos ${ }^{22}$}

La Biblioteca de Agustín Pablo de Ordeñana cuenta con 1.548 volúmenes; 296 libros sin encuadernar, librillos manuscritos sobre el gobierno de Francia y 2 mazos de guías de forasteros de España y Francia. Nuestro trabajo se ha centrado sobre esos 1.548 volúmenes (siendo 8 de estos volúmenes manuscritos) que forman un total de 711 títulos. Los principales problemas metodológicos se han centrado en el autor, la identificación de la obra y el idioma. Hay libros que no presentan duda alguna, aparecen con nombre de autor, título, idioma e incluso en alguma ocasión fecha de edición. Por ejemplo la Historia Eclesiástica del Abad de Fleury en idioma francés o El Peregrino en su patria de Lope de Vega Carpio en castellano. Libros como estos no ofrecen ningún problema en su clasificación.

En otras ocasiones se nos ofrece el título y el autor como la Historia de la Cantabria de Larramendi; en otras aparece únicamente el título impreciso de un libro que sólo puede corresponderse con un autor posible como La impugnación contra el Talmud de los judios, pero otras puede ser de varios autores como las Exequias de Luis I, la Historia del Cardenal Jiménez o la Recoleción de los Tratados de Paz, lo que hemos hecho en estas ocasiones es servirnos de todos las posibles autores y clasificarlo temáticamente.

El análisis de la biblioteca de Ordeñana cuenta además con un problema añadido: muchos de los libros que Ordeñana poseía están en francés y sin autor por lo que su búsqueda ha resultado bastante fatigosa. Pero tienen la ventaja de que la mayoría de los que están en esta situación son libros de temática religiosa como $E l$ Geremías o $E l$ Libro de los Jueces, lo que no nos ha impedido clasificarlos tanto por la temática como por el idioma.

Puede ocurrir también que nos haya aparecido un título definido, con un autor aparentemente claro, pero si profundizamos puede que aparezca la misma obra con otro autor distinto.

Con los idiomas el procedimiento ha sido el siguiente, en primer lugar hacer caso del idioma que nos decía el propio inventario. Si el inventario no decía idioma y el autor era castellano hemos supuesto que el libro era en castellano; si en el inventario

21. SOUBEYROUX, J. 1982. Pero también de CASTRO, C. 1996. pp 413-418 en el análisis del contenido de la Biblioteca de Campomanes.

22. Para este apartado las obras consultadas han sido principalmente las de PALAU Y DULCET, A. 1971; AGUILAR PIÑAL, F. 1981-1989 y obras de carácter general y particular del siglo XVIII y su cultura que se pueden ver en el apartado de Bibliografia. 
no decía idioma pero lo hemos encontrado en francés hemos intentado buscar cuándo fue su traducción al castellano si fue posterior a 1754 (año del inventario) hemos optado por el idioma original. Por ejemplo en el inventario aparece una Historia del Cielo que sabemos que es la del abate Pluche editada en París en 1739 y que no fue traducida al castellano hasta $1773 / 79$, pues bien, el idioma elegido en este caso ha sido el francés.

Algunos de los libros sólo los hemos encontrado en su original inglés o alemán y al castellano sabemos que no fueron traducidos hasta después de 1754; en ese caso, hemos optado por ponerlos en la edición francesa ya que, salvo contadas excepciones, todas las obras inglesas y alemanas pasaban primero por la lengua francesa antes de ser traducidas al castellano como por ejemplo la Géographie universelle del alemán Juan Hübner. Como es sabido, el problema en las traducciones son las muchas libertades que se tomaban los traductores a la hora de traducir esas obras e incluso los impresores, que compilaban, resumían, juntaban varios opúsculos bajo el título del primero. Ordeñana tiene la mayoría de sus obras en el lenguaje original en que fueron escritas.

Si difícil es buscar el autor, el idioma o el título de un libro, más difícil resulta encontrar el año de edición porque este dato raramente lo da el inventario. En este supuesto lo que hemos hecho ha sido copiar todas las posibles ediciones y apuntar como certeras aquellas que se acercaban a otros detalles que siempre vienen dados en el inventario como los volúmenes o el formato del libro; aunque esto no sea correcto para una clasificación temática no es impedimento errar en la fecha de edición.

Como todos los investigadores han reparado, lo más importante es la relación que podemos establecer entre libro y propietario; siempre es arriesgado, pero comprobaremos cómo en el caso de Ordeñana su biblioteca está perfectamente seleccionada y tiene una consonancia con un proyecto político, social e ideológico y con unas inquietudes mentales propias de su siglo. La Biblioteca de Ordeñana, en fin, es el mejor ejemplo de biblioteca ilustrada de la primera mitad del siglo XVIII español.

\section{Análisis de la Bibltoteca de Agustín Pablo de Ordeñana}

Entre el 20 y el 31 de julio de 1754 , por orden directa de Wall refrendada por Fernando VI, era requisada la casa de Ordeñana, mandados inventariar todos sus bienes y, cómo no, su fantástica biblioteca ${ }^{23}$. Lo mismo se hizo con la casa del marqués. Wall tenía necesidad de encontrar papeles inculpatorios contra ambos -debía justificar la drástica medida del destierro- y pruebas de enriquecimiento de los desterrados, pero no encontró demasiado. Es cierto que muchos de los libros de Ordeñana estaban prohibidos por el Tribunal de la Santa Inquisición ${ }^{24}$ pero esto no debía preocupar

23. AHN, Estado, leg. 5048.

24. Según DEFORNEAUX, M. 1973, la Inquisición era bastante laxa en esta materia y el contrabando por los principales puertos del país como Irún o Cadiz eran habituales, además gran cantidad de extranjeros traían sus libros a España y españoles en el extranjero también traían sus obras cuando regresaban definitivamente a su patria. De esta forma se fueron introduciendo toda clase de obras en la Península Ibérica. Hasta que no estalló el conflicto revolucionario en Francia no hubo un cierre de fronteras establecido por Floridablenca y un auténtico "cordón sanitario" a todo aquello que vieniera del exterior, sobretodo de Francia. El tráfico de libros fue moneda corriente durante la primera mitad del XVIII. 
mucho al ex-embajador inglés, el caballero Dick Wall. Más debía interesarle la posibilidad de encontrar papeles manuscritos, cartas -por ejemplo, las que se sabía se cruzaban con Nápoles, con la Farnesio- y, como no, las pretendidas órdenes de guerra dictadas por Ensenada, que es la causa principal esgrimida para lograr su caída.

La división temática que proponemos es la siguiente:

Libros de Historia y Geografia (Historia Civil, Historia Religiosa y Libros de Viajes y de Geografia).

Libros de Ciencias y Artes (Ciencias, Filosofia,Artes Mecánicas y Artes Militares).

Bellas Letras (Libros de Literatura, Diccionarios, Gramáticas y Periódicos).

Derecho (Temas civiles y temática religiosa).

Religión (Comentarios del Evangelio,Tratados Apologéticos y Doctrinales, Biblias, Libros de Devoción y Hagiografias).

Varios (principalmente Almanaques y Calendarios, Diccionarios Portátiles y Operas)

Un apartado de desconocidos donde se encuentran todos aquellos que nos ha sido imposible clasificar. (Tabla 1 ).

Tabla 1: Distribución de los temas

\begin{tabular}{|c|c|}
\hline 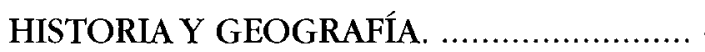 & 464 VOL ............ \\
\hline CIENCIAS Y ARTES.. & 283 VOL. \\
\hline BELLAS LETRAS..... & 247 VOL ............ 15,95\% \\
\hline ERECHO .......... & 243 VOL $\ldots \ldots \ldots \ldots$ \\
\hline RELIGIÓN & 230 VOL $\ldots \ldots \ldots \ldots \ldots . . . .14,85 \%$ \\
\hline VARIOS.................. & 55 VOL $\ldots \ldots \ldots \ldots \ldots . . . . .3,55 \%$ \\
\hline ESCONOCIDOS.. & $26 \mathrm{VOL} . . . \ldots \ldots \ldots \ldots$ \\
\hline
\end{tabular}

Tabla2: Distribución de los idiomas

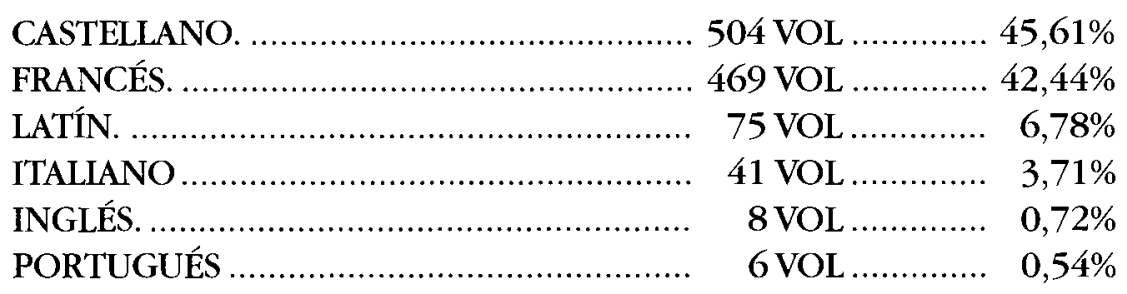

Este análisis cuantitativo nos muestra a un hombre de una sólida cultura e importante formación humanística y linguística (Tabla 1). Como buen ilustrado tenía en su biblioteca la mayoría de libros de Historia y Geografia con casi el 30\%; las Ciencias y Artes también eran de su interés aunque se le quedan un poco alejadas de este con un 18,28\%, los temas de Bellas Letras, Derecho y Religión están muy equilibrados, los tres rondan el $15 \%$. Ordeñana era un hombre de Letras, algo no muy difícil de encontrar entre los militares del siglo XVIII (piénsese en Juan, Ulloa, Cadalso) . Preocupado por la Teología -lo que era normal- estaba al corriente de los más importantes debates religiosos del momento como los del Abad de Prades; los varios con un 3,55\% son en su mayoría Almanaqes y Calendarios. 
mucho al ex-embajador inglés, el caballero Dick Wall. Más debía interesarle la posibilidad de encontrar papeles manuscritos, cartas -por ejemplo, las que se sabía se cruzaban con Nápoles, con la Farnesio- y, como no, las pretendidas órdenes de guerra dictadas por Ensenada, que es la causa principal esgrimida para lograr su caída.

La división temática que proponemos es la siguiente:

Libros de Historia y Geografia (Historia Civil, Historia Religiosa y Libros de Viajes y de Geografia).

Libros de Ciencias y Artes (Ciencias, Filosofia,Artes Mecánicas y Artes Militares).

Bellas Letras (Libros de Literatura, Diccionarios, Gramáticas y Periódicos).

Derecho (Temas civiles y temática religiosa).

Religión (Comentarios del Evangelio,Tratados Apologéticos y Doctrinales, Biblias, Libros de Devoción y Hagiografias).

Varios (principalmente Almanaques y Calendarios, Diccionarios Portátiles y Operas).

Un apartado de desconocidos donde se encuentran todos aquellos que nos ha sido imposible clasificar. (Tabla 1).

Tabla 1: Distribución de los temas

\begin{tabular}{|c|c|}
\hline & \\
\hline & 283 \\
\hline LETRAS ....... & 247 VOL. \\
\hline DER & 243 VOL.. \\
\hline RELIGIÓN . & $230 \mathrm{VOL} \ldots \ldots \ldots \ldots . . . . .14,85 \%$ \\
\hline VARIOS..... & 55 VOL... \\
\hline DESCONOCIDOS & 26 VOL $\ldots \ldots \ldots \ldots \ldots$ \\
\hline
\end{tabular}

Tabla2: Distribución de los idiomas

CASTELLANO $\ldots \ldots \ldots \ldots \ldots \ldots \ldots \ldots \ldots \ldots \ldots \ldots \ldots \ldots \ldots \ldots$
FRANCÉS.

Este análisis cuantitativo nos muestra a un hombre de una sólida cultura e importante formación humanística y linguística (Tabla 1). Como buen ilustrado tenía en su biblioteca la mayoría de libros de Historia y Geografia con casi el 30\%; las Ciencias y Artes también eran de su interés aunque se le quedan un poco alejadas de este con un $18,28 \%$, los temas de Bellas Letras, Derecho y Religión están muy equilibrados, los tres rondan el $15 \%$. Ordeñana era un hombre de Letras, algo no muy difícil de encontrar entre los militares del siglo XVIII (piénsese en Juan, Ulloa, Cadalso) . Preocupado por la Teología -lo que era normal- estaba al corriente de los más importantes debates religiosos del momento como los del Abad de Prades; los varios con un 3,55\% son en su mayoría Almanaqes y Calendarios. 
En la Tabla 2 podemos observar cómo los idiomas más utilizados por Ordeñana fueron el castellano $(45,61 \%)$ y el francés $(42,44 \%)$. Esto no debe extrañarnos ya que en esta primera mitad del siglo la corte hablaba en francés, y Ordeñana como cortesano conocía este idioma perfectamente; el latín (6,78\%) también se seguía utilizando en círculos cultivados pero en estos años ya empezaba a ser menos importante y había dejado paso a las lenguas vernáculas; el italiano (3,71\%) había sido el idioma extranjero más importante en época de los Austrias pero ahora dejaba su puesto preponderante al francés. Los libros en inglés $(0,72 \%)$ y portugués $(0,54 \%)$ son los menos, pero como luego veremos Ordeñana estaba aprendiendo inglés por el gran número de diccionarios y gramáticas que poseía.

\section{Análisis cualitativo de la Biblioteca de Ordeñana}

La Biblioteca de Agustín Pablo de Ordeñana tiene 1548 Volúmenes y unas 711 obras; la Biblioteca del Marqués de la Ensenada tiene 838 volúmenes y unos 190 títulos y la Biblioteca de Campomenes tiene 4.995 volúmenes más otros tantos "libros prohibidos" que hacen un total aproximado de 6.000 volúmenes.

Tabla3: Las tres bibliotecas

\section{ORDEÑANA}

HISTORIA Y GEOGRAFÍA
CIENCLAS Y ARTES
BELLAS LETRAS
DERECHO
RELIGIÓN
VARIOS
DESCONOCIDOS.

\section{ENSENADA}

$32,69 \%, 274 \mathrm{Vol}$

$19,21 \%, 161 \mathrm{Vol}$

$10,26 \%, 86 \mathrm{Vol}$

$20,76 \%, 174 \mathrm{Vol}$

$9,54 \%, 80 \mathrm{Vol}$

$7,5 \%, 63 \mathrm{Vol}$

\section{CAMPOMANES.}

$23,0 \%, 1154 \mathrm{Vol}$

$24,0 \%, 1169$ Vol

$18,7 \%, 906 \mathrm{Vol}$

$26,0 \%, 1261 \mathrm{Vol}$

$7,8 \%, 366 \mathrm{Vol}$

Libros de Historia y GeOgrafía.

En las tres Bibliotecas los libros de Geografia e Historia ocupan una importante posición siendo en las Bibliotecas de Ensenada y Ordeñana donde hay una mayor proporción de estos frente a los libros de otras materias. En la siguiente tabla (Tabla 4) hemos distribuido los temas de Historia en Historia Civil, Historia Religiosa, Geografia y Viajes con el fin de saber cuántos libros pertenecen a cada sección.

Tabla 4: Distribucción libros de Geografía e Historia

\begin{tabular}{llcc} 
& \multicolumn{1}{c}{ ORDEÑANA } & ENSENADA & CAMPOMANES \\
HISTORIA CIVIL. & $64,87 \%, 301 \mathrm{Vol}$ & $62 \%, 170 \mathrm{Vol}$ & $59,79 \%, 1154$ \\
HISTORIA RELIGIOSA. & $21,76 \%, 101 \mathrm{Vol}$ & $23,72 \%, 65 \mathrm{Vol}$ & $33,27 \%, 384$ \\
VIAJES Y GEOGRAFÍA. & $13,36 \%, 62 \mathrm{Vol}$ & $14,23 \%, 39 \mathrm{Vol}$ & $7,01 \%, 81$
\end{tabular}

En la Biblioteca de Ensenada la Historia Civil es la más significativa, los libros de historia que posee son los más vendidos de la época como la Historia de Méjico de 
Solís y Salazar, la Historia de España de Juan de Mariana o la Historia Civil de España de Jesús Belando. Tiene también los diccionarios más importantes del momento como el Dictionnaire bistorique et critique de Pierre Bayle o el Gran Diccionario Histórico de Moreri en castellano y francés. Ensenada mostró un gran interés por la Arqueología y la Historia; uno de sus proyectos fue potenciar las excavaciones arqueológicas del Albaicín durante su destierro y siempre estuvo en contacto con los ingenieros que trabajaban en Cartagena, que le mandaban hallazgos de la romana Cartago Nova. Posee varios libros sobre ruinas arqueológicas y sobre "pinturas antiguas" lo que demuestra sus intereses en este sector.

La Historia Religiosa parece no interesar a Ensenada con 65 volúmenes del total de su biblioteca; posee, por ejemplo, la España Sagrada del Padre Flórez y la Histoire ecclésiastique de Fleury. Esto contrasta con su fama de jesuitón, pero, como dice un panfleto anónimo, "aunque parecía buen cristiano, no se le conoció confesor". En cualquier caso, sus inquietudes por la historia religiosa no ocupaban mucho especio en su biblioteca; desde luego, menos que lo que demuestran Ordeñana y el perseguidor de jesuitas Campomanes.

Ensenada se interesó más por las obras de Geografia teniendo en su Biblioteca tres de las obras más importantes del momento como el Atlas de Juan de Beaurain, el Atlas Mayor de Jean Blaeu o el Dictionnaire géograpbique de Antonio Bruzen de la Martiniere. Su mayor proyecto cartográfico hubiera sido la realización de un Mapa de España con la ayuda de dos de los mejores científicos del momento Jorje Juan y Antonio de Ulloa, ambos fueron amigos y complices del marqués en su política cultural y de espionaje industrial ${ }^{25}$. Entre los viajes destaca la Relación Histórica del Viaje a la América de Antonio de Ulloa.

El grueso de la Biblioteca de Ordeñana lo forman los libros de Historia y Geografia con un $29,97 \%$ del total. De estos el $64,87 \%$ son libros pertenecientes a Historia Civil.Aparte de los diccionarios históricos que posee, iguales a los del marqués, Ordeñana posee diversas historias de Inglaterra, Francia, Roma, Italia y las Indias. Inglaterra era una importante potencia marítima y era conocido que poseía ya un imperio comercial molesto para los intereses españoles sobre todo después del tratado de Utrech en 1713. Ordeñana lee bastante sobre Inglaterra posee la Historia de Inglaterra de Rollín, una Historia del Parlamento de Inglaterra, la Vida de Oliverio Crombel y una Política de Bacon, Chanciler de Inglaterra. También es evidente su interés por la historia de Francia, especialmente por el tiempo del adorado Luis XIV. Voltaire aparece en su biblioteca con dos de sus obras históricas, el Siécle de Louis XIV y la Historia de Carlos XII en italiano; ambas obras, lógicamente, figuraban ya en los Indices de la Inquisición.

Posee obras de espíritu regalista comoDell'istoria civile del Regno di Napoli de Pietro Giannone en la que el autor denuncia cómo la iglesia siempre está interesada y presta a aprovecharse de las debilidades humanas y abogaba por la defensa del poder civil sobre el religioso. Esta obra le valió al autor la excomunión. El regalismo inundó el siglo XVIII. Ordeñana estuvo tras la firma del Concordato de 1753, la pieza más regalista del siglo, y solicitó la ayuda de Don Gregorio Mayans para la edición de un escri- 
to que sirviera para instruir a los españoles sobre las regalías. De esta forma surgieron las Observaciones sobre el Concordato de 1753 cuya difusión se vio obstaculizada por la caída de Ensenada y permanecieron inéditas hasta su publicación a finales de siglo por Valladares ${ }^{26}$

Es muy interesante el Diccionario Histórico Portátil, Ordeñana en sus desplazamientos aprovecha para aprender más, no solo tiene este diccionario portátil sino que posee dos diccionarios portátiles aunque desconocemos de qué tratan su posesión es ya bastante significativa.

La Historia Religiosa ocupa el 21,76\% del total de los libros de Historia, pero pese a su relativa desproporción los libros son tan interesantes como la Histoire des variations de l'église protestante de Bossuet, las dos obras más importantes del Adad de Fleury su Histoire Eclesiástique y el Discours sur l' histoire ecclesiástique o la Historia del Antiguo y Nuevo Testamento por Agustín Calmet, todas condenadas por la Inquisición.

Los libros de Geografia y Viajes ocupan el 13,36\% del total.Tiene obras muy importantes como el Compendio de la Antigua y Nueva Geografía de Juan Hübner o $E l$ Orinoco Ilustrado del Padre Jose Gumilla. Un gran interés muestra por los Diccionarios de Geografia posee tres diccionarios geográficos el Dictionnaire géographique portatif...traduit de l'anglois sur la 13e édition de Laurent Echard, par M.Vosgien y el Dictionnaire géographique, historique et critique de Bruzen de la Martiniere. Del tercer diccionario desconocemos su autoría. Es muy interesante la siguiente carta de Huéscar a Carvajal donde se nos da la siguiente noticia de Ordeñana ${ }^{27}$ :

"Abí te embío un Diccionario geográfico que, aunque tiene tal cual falta por lo que toca a España por nuestra culpa, es muy cómodo porque se haya todo en él. No se le des a nadie, porque quiero que le traduzcan en español. Otro envío a Hordeñana con la misma protexta".

HUÉSCAR a CARVAJAL. Versailles, 6 mazo de 1747.

Ozanam cree que se trata del Dictionnaire géograpbique portatif. Esta es una pequeña muestra del interés de Ordeñana por todo lo que se producía en el extranjero y cómo era una autoridad en el terreno de la cultura de la primera mitad del XVIII que nos queda por descubrir ya que como luego veremos tomó también parte en otras actividades culturales de sumo interés.

Los libros referidos a viajes son abundantes destacando el Viaje a la América de Ulloa, los Viajes de Cyro de Ramsay o la Histoire généreles des voyages del Abate Prévost.

La Biblioteca de Campomanes la conocemos en menor medida ya que sólo tenemos los datos cuantitativos del estudio de Soubeyroux y los aportados por Concepción de Castro. Aun así podemos observar cómo su interés por la historia (23\%) ocupa un importante espacio en su biblioteca como hombre de letras que era y sorprende

25. Op. cit GÓMEZ URDÁÑEZ.

26. ALCARAZ GÓMEZ, J.F. 1995, p. 572.

27. OZANAM, D. 1975, p. 153. 
ver cómo es él el que tiene una mayor proporción de obras de historia religiosa con un $33,27 \%$ frente al $23,72 \%$ de Ensenada y el $21,76 \%$ de Ordeñana.

\section{CienCIAS Y ARTES}

Es sabido que el siglo XVIII conoció un gran interés por las ciencias, lo que se tradujo en la gran cantidad de obras de divulgación que se escribieron, en general, libros fáciles de leer puestos al alcance de mentalidades inquietas.

Ensenada mostró entusiasmo por las ciencias, sobre todo por aquellas que tenían que ver con sus intereses por los saberes prácticos; él era un hombre de acción más que de reflexión y su escasa formación intelectual previa no le impidió conocer algunas de las obras más importantes del momento. Del 19,21\% del total de los libros de Ciencias y Artes que forman su biblioteca el 77,63\% y 125 volúmenes son libros de Ciencia; el 11,8\% con 19 volúmenes están relacionados con las Artes Militares; el 5,5\% con 9 volúmenes son libros de Filosofía y el 3,10\% con 5 volúmenes, libros de Artes Mecánicas. Entre las obras de Ciencias que posee son de destacar el Compendio Matemático de Tosca, el Espectáculo de la Naturaleza de Pluche, el Diccionario de Trevoux., el Arte de la Tintura de Monsieur Hellot o el Cultivo de Tierras de Miguel José de Aoiz.

Ensenada estuvo siempre ligado al mundo de la marina y lo militar que conocía y dominaba. Es sabido que después de Aquisgrán se pretende reforzar la marina española y formarla práctica y teóricamente, para lo que se refuerza institucionalmente la formación con la creación de centros que van desde academias a hospitales u observatorios y con la edición de numerosos libros, muchos de los cuales se dedicaron al marqués o es seguro que se le regalaron por ser considerado el gran portector de la Marina. Así, tenía por ejemplo el Curso Militar de Matemáticas de Padilla o numerosos atlas y cartas de reciente factura. En estas escuelas verdaderamente superiores no sólo se estudiaban matemáticas puras, sino que también se incluía todo lo referente a su aplicación: pólvoras, construcción de arsenales y almacenes, calibres de piezas, afustes, montajes, punterías, construcción de baterías o trenes. Matemáticas, Física y Química encontraron en la Marina ensenadista el lugar común que nunca habían conocido en España. Se consiguió unir lo teórico con lo práctico en centros militares como el Colegio de Medicina y Cirujía de Cádiz (1748) o el Observatorio Astronómico, también en Cádiz, con el valioso apoyo de Antonio de Ulloa y Jorge Juan (1751). Ordeñana, más "de letras", sin embargo, como pantófilo, se interesó igualmente por ese mundo. Antonio Rodríguez Villa en su libro sobre Ensenada recogió algunas cartas de Ordeñana y Antonio de Ulloa; en una de ellas los dos hombres se consultan sobre la construcción de otro observatorio astronómico y la formación de una colección de minerales y de antiguedades; en la otra sobre la construcción de un Canal para Castilla ${ }^{28}$.

La Biblioteca de Ordeñana tiene 283 volúmenes de Ciencias y Artes que forman el $18,26 \%$ del total de su biblioteca. De éstos el $49,1 \%$ con 139 volúmenes son obras de Ciencias; el $40,2 \%$ con 114 volúmenes son obras de Filosofia; el 5,3\% con 15 volúme-

28. RODRÍGUEZ VILLA,A. 1878, P. 357. 
nes son obras de Artes Mecánicas y el 5,3\% con 15 volúmenes son obras de Arte Militar. Los libros de Ciencia que posee son lo más adelentado del momento, tiene el Dictionaire de Trevoux, el Spectacle de la nature ou entretiens sur l'bistoire naturelle et les sciences de Pluche, el Traité de la Culture des terres y el Traité de la conservation des grains de Duhamel, las Memorias para la Historia de las Ciencias y las Artes de Trevoux o la Historia Natural de Buffon, teniendo la obra magna de la Ilustración Francesa el Dictionnaire raisonné des sciences, des arts et de métiers ou Enciclopedie cuyos dos primeros volúmenes aparecen entre 1751 y 1752. Ambos los tiene Ordeñana (también Carvajal, pero no Ensenada).

Las matemáticas -de "ciencia forastera" (Feijoo) a "ciencia del siglo"- sufren un gran impulso en este siglo y como consecuencia de ello, la astronomía y otras aplicaciones como la cartografia. La mayoría de la opinión pública cultivada mostraba gran interés por estos temas, especialmente por el debate existente sobra la figura y medición de la tierra. Ordeñana estuvo interesado en este debate y tiene un libro que como el de Jorge Juan y Antonio de Ulloa Observaciones Astronómicas y Prysicas lo demuestra, pero también algunos otros sobre las teorías de la figura de la tierra o ensayos sobre cosmología. Pero, no sólo hubo debates teóricos: los distintos estados europeos potenciaban estos estudios enviando expediciones de científicos a medir la tierra. Fernando VI no fue menos y envió al científico Antonio de Ulloa a medir los grados del meridiano terrestre para conocer la verdadera figura y magnitud de la tierra. Además Ordeñana tenía en su casa un telescopio de metal lo cual es un importante dato que asegura su interés por la astronomía.

Los temas filosóficos ocupan un destacado lugar en su biblioteca, con un 40,2\% del total. Para los ilustrados el hombre es un ser educable y por ello conceden tanta importancia a la educación tanto de la juventud en general como de la de los príncipes y hombres de gobierno. Las obras sobre este asunto son muy abundantes durante todo el siglo y en la biblioteca de Ordeñana nos encontramos con las más representativas como Della publica felicitá aggetto de buoni principi de Muratori, De la maniére d'enseigner les belles-lettres par rapport á l'esprit et au coeur y la Educación de la Juventud de Rollín o el Verdadeiro metbodo de estudiar del portugués Luis Antonio Verney.

Tiene las Tesis de Juan Martín de Prades, que escribió varios artículos para la Enciclopedia pero que se hizo realmente famoso por su tesis leida en 1751 en la Soborna donde sus contenidos contra la espiritualidad del alma, la moralidad, el origen de la sociedad, el derecho natural, la religión y la divinidad de Jesucristo, cuyos milagros comparaba a los de Esculapio, le valieron para que la Universidad de París le sometiera a un proceso y fuese excomulgado. Prades fue uno de los primeros colaboradores de la Enciclopedia, y de los primeros que sufrió represión por sus ideas. Otra obra polémica fue los Caractéres de Théophastre, traduit du grec avec les moeurs de ce siécle de Jean de La Bruyére, obra que fue declarada injuriosa y satírica contra Inocencio III, los Príncipes de la Iglesia y la Compañía de Jesús por la Inquisición y condenada por el Index en 1756 cuando en realidad la obra lo que hace es denunciar la banalidad de los cargos públicos, la desigualdad de las fortunas, el lujo de los financieros, y criticar la política de conquistas. Esta obra se ocupa del conjunto de la sociedad francesa y ejerció una profunda influencia. Pocas obras fueron tan admiradas en la época. Otra obra polémica y novedosa fue el Essay on buman understanding de 
Locke, que Ordeñana tiene en sus versión francesa. La Inquisición la condenó por incitar al deismo, a proposiciones temerarias y escandalosas.

Locke, La Bruyére, Prades, Rollín son alguna de las autoridades intelectuales del momento, sin duda, "peligrosas", pero Ordeñana tiene además de sus obras otra no menos comprometida: La Fable de Abeilles, oú les vices privés font la properité publique de Bernardo Mandeville. Esta obra fue escrita en 1714 y en 1715 estaba ya condenada por el tribunal de Middlessex ya que levantó numerosas protestas de católicos y protestantes por su apología del racionalismo y del materialismo aplicadas a la moral y la política. El autor se sirve en realidad de una colmena y de sus abejas para exponer su teoría empírica del conocimiento, su relativismo moral y la justificación de los vicios. Sus ideas pasaron a la Enciclopedia e influyeron en Helvetius y los utilitaristas del siglo pasado. Ordeñana cuenta además con las obras de Rousseau.

Las obras sobre Artes Militares y Artes Mecanicas ocupan la posición más reducida de esta sección con un 5,3\% cada una. Las primeras están en estrecha relación con el mundo de las Academias como los tres Diccionarios Militares que tiene, una Práctica de Maniobras, el Curso Militar de Matemáticas de Padilla o el Art de la guerre par Principes et par regles de M' Le Marechal de Puységur. Las Artes Mecánicas no parecen interesar tanto a Ordeñana y estas se reducen a algunos tratados de arquitectura, de puentes o de jardines, en estrecha relación con su cargo de director de las obras del Real Palacio de Madrid.

Campomanes es en proporción el que más libros tiene dedicados a este asunto con un $24 \%$ de su biblioteca y 1.169 volúmenes. Los libros de filosofía de Campomanes son bastante amplios tiene a Platón, Aristóteles, Cicerón, Séneca, Bacon, Erasmo, Vives, Leibniz, Bayle, Locke. Su interés científico le llevó a tener obras de Newton, Galileo, Copérnico, Ptolomeo. Obras francesas de la nueva física experimental o de química, obras de anatomía, cirugía, temas médicos, terremotos, botánica o libros de matemáticas.

\section{BeLlas Letras}

La Biblioteca del Marqués de la Ensenada relativa a este apartado es muy pobre; sólo posee 86 volúmenes que forman el 10,26\% del total. Las obras están en su mayoría en castellano. Ensenada sabía muy poco latín, pero sí francés. No era hombre de letras aunque posee algunas de las obras más divulgadas del mometo como las Cartas Eruditas de Feijoo, las Memorias Literarias de Luzán o unas Poesías de Quevedo. El marqués apenas leía y era un hombre más de oído que de lectura, su mundo era lo práctico y lo militar y no lo literario. Tiene el Dicionario nuevo de las lenguas española y francesa de Francisco Sobrino, el más importante del momento, pero en temas literarios quizás le bastara con su contacto permanente con el Padre Isla.

La Biblioteca de Ordeñana con un 15,95\% del total y 247 volúmenes demuestra el interés de este "militar" por la literatura. De estos, el 75,7\% y 186 volúmenes son obras propiamente literarias; el 12,9\% y 33 volúmenes son diccionarios; el 8,5\% y 21 volúmenes corresponden a gramáticas y un $2,83 \%$ y 7 volúmenes a publicaciones periódicas. 
Entre las obras literarias destacan las latinas y castellanas por encima de la literatura francesa o italiana. Los autores latinos que posee son los clásicos Ovidio, Quinto Curcio, Quintiliano, Cayo Cornelio Tácito, Virgilio, Lucrecio, Horacio, Terencio, Fedro o Casto Valeyo Paterculo; muchas de sus obras están en castellano, en latín o en ambas, pero nos ha sido en muchas ocasiones imposible de fijar con seguridad la lengua ya que las ediciones han sido durante años muy numerosas y en varias lenguas. Pero el conocimiento del latín y el gusto de Ordeñana por leer las obras en idioma original nos inclina a pensar en el latín como predominante en todas estas obras.

En castellano destacan las Memorias Literarias de París. En esta obra Ignacio de Luzán resume y ordena las informaciones y observaciones que acumuló durante tres años que vivió en la capital francesa, se relata cómo los franceses aprendían y ejercían sus actividades relacionadas con la vida del "espíritu"; un "espíritu" que tanto amaba Ordeñana, pero también las Cartas Eruditas y el Teatro Crítico Universal de Feijoo o las obras del ilustrado valenciano Gregorio Mayans y Siscar tales como las Cartas de Don Nicolás Antonio y de don Antonio de Solís y la Vida de Miguel de Cervantes Saavedra, la Vida de Don Quijote de la Mancha de Miguel de Cervantes. Ordeñana solicitó la ayuda de Mayans para una de las ediciones del Quijote ${ }^{29}$. Por lo tanto, estamos ante un personaje que no solo se preocupa de lo que se produce fuera de España sino que también está en contacto con la corriente que pretende revitalizar los clásicos castellanos, como el Quijote, y en general la "cultura española".

De la literatura francesa podemos destacar las obras de Racine y Moliere y de la italiana la Della perfetta poesia italiana de Muratori.

Llama la atención de esta biblioteca el gran volumen de diccionarios y gramáticas en diferentes idiomas que posee. Ambos apartados forman el 3,5\% del volumen total de la biblioteca. Los diccionarios son los siguientes:

Nuevo Diccionario Español-Inglés.

Diccionario Francés-Inglés.

Diccionario Inglés-Español en inglés.

Vocabulario Italiano-Francés.

Diccionario Francés-Latín.

Diccionario Trilingue.

Diccionario Latino-Francés.

Diccionario Italiano-Francés.

Diccionario Latino-Francés.

Diccionario Castellano-Latín.

Diccionario de la Lengua Castellana.

Diccionario Latino.

Vocabulario Español en Inglés.

Vocabulario Toscano-Castellano.

Diccionario Español-Francés.

Vocabulario Italiano.

Diccionario Inglés-Español.

Diccionario de la Fabula. 


\section{Diccionario de Sobrino}

Diccionario de Mitología.

De este análisis podemos deducir que Ordeñana conocía perfectamente el francés y lo intentaba con el inglés; su dominio del francés es tal que se permite tener diccionarios Francés-Inglés o Franceses y Latinos. Este dominio de la lengua francesa ha quedado demostrado en la Tabla 2: del $72 \%$ de los libros analizados para esta ocasión, un $45,62 \%$ están en castellano y un $42,44 \%$ en francés; tan solo el $0,7 \%$ en inglés.

El afán por el estudio de Ordeñana lo muestran los abundantes libros de gramática que posee. Según el inventario tiene:

Nueva Gramática Inglesa y Francesa.

Gramática Inglesa y Francesa.

Gramática Española en inglés.

Gramática Inglesa en inglés.

Nueva y Perfecta Gramática Francesa.

Gramática Francesa.

Abreviación de los Principios de la Gramática Francesa.

Gramática Castellana.

Explicación de las Reglas de Géneros y Pretéritos.

Epitome de la Elocuencia.

Ortografía Española.

El Arte Explicado y Gramática Perfecta.

Reglas de Ortografía.

Primeros Rudimentos de la Gramática.

Las Ocbo Partes de la Oración Gramática.

Ortografía Toscana.

Llava de Oro de la Gramática.

Gramática de la Lengua Tudeica.

Diabogas de Recta Pronunpciationi lingue.

Reglas de la Poesía en General.

El uso de gramáticas por parte de Ordeñana es abundante: no sólo tiene gramáticas de iniciación sino también de perfeccionamiento. La enseñanza humanista llegó a su máximo explendor en el reinado de Fernando VI. En 1714 se fundó la Real Academia Española de la Lengua por el Marqués de Villena para poner freno al excesivo afrancesamiento de la Corte. Para este fin la Academia publicó el Diccionario de Autoridades (1726-1739), una Ortografía (1741) y una Gramática de la Lengua Castellana (1771). Ordeñana posee las dos primeras publicaciones de la Academia. Pero también se formaron otras academias como la Academia Valenciana de 1743 fundada por Mayans y cuya existencia fue efímera; también de este período fueron la Real Academia de Buenas Letras de Barcelona y la Real Academia de las Buenas Letras de Sevilla, ambas fundadas en 1751 .

Los manuscritos encontrados son dos: unas Poesías de Quevedo y los Zenones Famosos de Antonio Xara-Quemada. En esta obra están comprendidos todos los Zenones que han sido memorables a lo largo de la historia, es un libro de alabanza al Zenón 
del momento, al Marqués de la Ensenada y Ordeñana posee este manuscrito de alabanzas a su jefe y amigo. El manuscrito termina así:

"mayores méritos que estos grandes títulos le condujeron a ellos y si bien puede todavía conseguir otros más, no podrá nueva gloria, que no admite incremento la que ya tiene. Esto es y será...." ${ }^{30}$.

Es sabido que la prensa periódica muestra ya a mediados del XVIII un notable interés. Ordeñana tiene el primer periódico del siglo, el Diario de los Literatos de España fundado por Martínez Salafranca, Francisco Manuel de la Huerta y Leopoldo Gerónimo Puig. Se fundó en 1737 y desapareció en 1742 . Este periódico contenía fundamentalmente reseñas de libros y un compendio de los escritos de autores españoles. Esta obra periódica se publicaba cada tres meses y Ordeñana posee siete volúmenes. Estar abonado a un periódico que fundamentalmente se dedica a reseñar libros como este Diario de los literatos demuestra el caracter nuestro "político" ilustrado.

Campomanes tiene 906 volúmenes en este campo con un 18,69\% del total de su biblioteca ocupando el cuarto puesto de sus preferencias. Como buen ilustrado era la antiguedad clasica la que más le atraía tiene a Homero, Píndaro, Petronio, Esopo, Fedro, Juvenal, Virgilio, Horacio, Lucano, Cicerón o Julio César entre otros. También las comedias de Aristófanes, en griego. Fuera del período de la antigüedad tiene a Dante, Nebrija, Jorge Manrique, el Quijote, obras de Gracián, Quevedo, son algunos de los autores más representativos de su biblioteca.

\section{Libros De Derecho}

Si Ensenada poseía pocos libros de Bellas Letras, con los libros de Derecho no ocurre lo mismo. Ensenada posee una importante biblioteca sobre estos temas ya que su mundo no son las letras, ni la teoría sino lo práctico, lo útil aquello que le sirve para sus planes y proyectos políticos y sobre todo aquello relacionado con lo naval, con lo marino y lo comercial. Su biblioteca de Derecho ocupa un 20,76\% del total con 174 volúmenes, de estos el 78,7\% y 137 volúmenes pertenecen a temas civiles; el 13,2\% con 23 volúmenes a temas militares; el $5,1 \%$ con 9 volúmenes a temas religiosos y el $2,87 \%$ con 5 volúmenes son diccionarios. Es en este tema donde Ensenada y Ordeñana tienen la mayoría de sus libros en común. Por esta razón vamos a comentar lo más destacado de la Biblioteca de Ordeñana relacionándolo con la del Marqués.

Ordeñana con el 15,69\% de libros de Derecho los tiene distribuidos de la siguiente manera; el $76,1 \%$ y 185 volúmenes es de temática civil; el $15,2 \%$ y 37 volúmenes es de temática militar; el $6,5 \%$ y 16 volúmenes es de temas religiosos y el $2 \%$ con 5 volúmenes es de diccionarios.

Tanto a Ordeñana como al resto de los ensenadistas y políticos del momento les interesaba el comercio y el asunto candente de la libertad comercial en los mares (quizás les interesara la obra de Grocio más por eso que por ser el "fundador" del Derecho Internacional). Holanda e Inglaterra tenían un importante imperio comercial que 
estaba haciendo mella en los intereses españoles. España todavía poseía sus colonias en ultramar y este comercio seguía siendo una importante fuente de ingresos para el erario español y para una tupida red de comerciantes particulares. Los libros que ambos estadistas poseen de Juan Jacobo Grocio, Mare Liberum y De iure belli ac pacis tratan de demostrar cómo el comercio libre es un derecho primario y cómo sólo con un poder fuerte se podría favorecer la expansión y el reparto coloniales en orden y en paz. Ordeñana tiene también el Comercio de Holanda de Francisco Javier Goyeneche (¿familiar suyo?), donde se relata el floreciente comercio de los holandeses, útil y seguro en todo el mundo, y cómo lo han hecho ellos. Ordeñana cuenta además con las Consideraciones sobre el Comercio de la Gran Bretaña de Joshua Gee, el Mare clausum de Dominio Maris de Juan Selden o el Tratado Jurídico-Político de Contrabando de Pedro González de Salzedo así como también un informe de la Compañía del Real Asiento de la Gran Bretaña.

El siglo XVIII ofrece también otros interesantes debates como el del derecho natural y su relación con el poder. El derecho va evolucionando debido al progreso en las ciencias, al descubrimiento de nuevas tierras, a la concepción laica de la naturaleza donde el derecho se separa de la religión y la política de la teología. El derecho cambia porque cambia el marco económico en el que se empieza mover, el del incipiente capitalismo comercial. Los nuevos teóricos del derecho natural invocan la utilidad general, los derechos del individuo y el estado de naturaleza. Este derecho no ofrece ningún problema al absolutismo y permite su justificación. En la Biblioteca de Ordeñana podemos encontrar los Principes du droit naturel y los Principes du droit politique de Burlamaqui y en ambas -en la de Ordeñana y el marqués- el De iure nature et gentium de Samuel Puffendorf; ambos junto con Grocius son los máximos representantes de esta corriente y éste último influirá decisivamente en enciclopedistas del tamaño de Rousseau.

Ordeñana sólo cuenta con la obra de un arbitrista: Sancho de Moncada y su Restauración Política de España. En este libro aparece ya de una forma clara la idea de que los problemas de España solo pueden tratarse desde el punto de vista de la intervención del Estado para que las soluciones sean eficaces. Este libro es "patriótico" en el sentido de español, se escribe pensando en España y sentó las bases económicas y sociales de una conciencia "patriótica" en la linea de la obrita "Lo que hay de más y de menos en España... de José de Campillo. Ensenada también tiene un único arbitrista en su biblioteca, pero es el de Miguel Caxa de Leruela Restauración de la antigua abundancia de España, un texto "agrarista" en contra del mercantilismo de Moncada.Ya del XVIII, cuentan con la divulgadísima obra de uno de los últimos "arbitristas": Teórica y Práctica de Comercio y Marina de Gerónimo Uztariz.

Ordeñana cuenta en su biblioteca con el Corps de Droit Frederic o Código Prusiano. En tiempos tanto de Fernado VI como de Carlos III hubo numerosos intentos por copiar este código. Durante el ministerio de Ensenada Mayans recibió muchas invitaciones para copiarlo.Los dos amigos poseen libros tan importantes como las Obras de Bossuet, los Intèrets des puissances de l'Europe de Rousset de Missy, o la Novísima Recopilación.

Los libros de derecho referidos a temas religiosos son escasos, lo civil empieza a dominar a lo religioso. Los estadistas defienden lo civil e intentan favorecer los poderes del monarca: de ello la mejor prueba es el Concordato de 1753 . De entre estos 
libros los que podemos destacar son el Novus Thesaurus Juris civilis et canonici o el Dictamen en justicia sobre la jurisdicción del Real Patronato de Hontalba y Arce (éste sólo lo tiene Ordeñana).

El Marqués estaba más relacionado con la práctica política y económica de Francia que Ordeñana. Las leyes y los reglamentos prácticos de este país que posee el marqués así lo demuestran. Ordenanzas y libros sobre milicias francesa y las dadas por Luis XIV de Francia dominan en la Biblioteca de Ensenada. Tanto Ordeñana como él y el resto de ensenadistas amaban a Luis XIV y su gobierno. Miraban hacia la política del Rey Sol y estaban al tanto de todo lo que en el país vecino se hacía en esta materia.

Campomanes, con un $26 \%$ de libros de Derecho del total de los libros de su biblioteca, es el que, con un total de 1261 volúmenes, tiene más que los otros dos: algo normal si recordamos que Campomenes era jurista. También en su biblioteca existe un dominio del Derecho Civil sobre el Eclesiástico ${ }^{31}$.Tenía todo Heinecio, el Novus Thesaurus civilis et canonici de Meerman, el Código de Teodosio y las Instituciones de Justiniano. Los más abundantes son los libros de Derecho español, antiguos Fueros y ordenanzas castellanas, fueros de Vizcaya, Alava, Guipúzcua y Aragón entre otros. El Derecho natural estaba bien representado por Grocio, Puffendorf, Burlamaqui o Felice. Posee un rico repertorio regalista con Van Espen a la cabeza; le siguen Bossuet, Fleury, Marca o Beccaria. Entre sus libros económicos se ecuentran arbitristan del XVII y autores españoles del XVIII: Patiño, Uztariz, Ulloa. También representantes del mercantilismo liberal como Josiah Child. En 1785 Campomanes añadió a su biblioteca The Wealth of Nations que le envió el propio Adam Smith.

\section{LIBROS RELIGIOSOS}

Es la materia menos representada de las tres bibliotecas estudiadas. Como hemos podido observar en la Tabla 1, Ordeñana posee $14,85 \%$ con 230 volúmenes; Ensenada el $9,54 \%$ con 80 voúmenes y Campomanes un 7,8\% con 366 volúmenes. Lo más curioso es la desproporción que supone estos libros si lo comparamos con el resto de los temas, salvo en el caso de Ordeñana que mantiene su equilibrio con temas como el del derecho -15,69\%- o las Bellas Letras con un -15,95\%-. En la polémica sobre la religiosidad no entraremos, pero sí hacemos notar que de las tres bibliotecas han desaparecido prácticamente los típicos misales, hagiografias o libros marianos.

La Biblioteca de Ensenada sufre un importante descenso porcentual en temas religiosos: la religión no parece ser un tema que preocupara al marqués, a pesar de que aparentemente era muy religioso; él mismo lo dice en una carta que escribió a Valenti y que aparece recogida en Gomez Urdáñez.

"Busco dinero y fuerzas de mar y tierra y no teologías" ENSENADA a VALENTI, 1752.

31. Así lo demuestra Soubeyroux, aunque C. de Castro dice que "los más numerosos seguían los volúmenes de Derecho, parte de ellos en latín y la mayoría de Canónico", Soubeyroux, J., op. cit. y C. de Castro, op. cit. Como la autora dice, el estudio de Soubeyroux está hecho sobre el catálogo de 1840-42. 
Ensenada tiene vidas de santos como la Vida prodigiosa del V.P. Fr. Sebastián de Náxera de Fr. Pedro de la Assumpción; la Novena y Compendio de la vida de San Francisco de Sales de Juan de Ferreras o la curiosa Historia puntual y prodigiosa de la vida, virtudes y milagros de la Beata Maria de la Cabeza, digna esposa del glorioso San Isidro Labrador, patrón de Madrid del jesuita Francisco Antonio Serrano. Lo más importante de esta biblioteca es la posesión de un tomo de la Biblia Caste-
llana. Las traduciones de la Biblia al castellano son escasas; leer la Biblia en lengua verllana. Las traduciones de la Biblia al castellano son escasas; leer la Biblia en lengua vernácula estuvo prohibido en el siglo XVIII y para leerla en latín hacían falta permisos
especiales nada fáciles de conseguir, pero las Biblias entraban en nuestro país por diversos canales, bien conocidos ya por los trabajos de Deforneaux. La Biblia que posee Ensenada son Los cinco Libros de la Sacra Ley interpretada en Lengua Española, conforme a la divina tradición de José Franco Serrán en 1695. También es importante el Histoire critique du vieux Testament $\mathrm{y}$ la Histoire critique du texte du Nouveau Testament de Richard Simon que es el fundador de la modema texte du bíblica y que Ensenada tenía.

Ordeñana era un hombre más preocupado por la teología. Los libros bíblicos son muy abundantes. Posee tres versiones de Biblias y varios Diccionarios Bíblicos; tiene la Biblia de Duhamel, la Biblia Sacra y la Santa Biblia en francés; el Dictionnaire bistorique, géographique, critique, cronologique et littéral de le Bible de Agustín Calmet, una Explicación de la Biblia, un Diccionario de la Sagrada Escritura y un Diccionario de la Biblia en francés. Pero además una gran cantidad de libros relaDiccionario de la Biblia en francés. Pero ademas una gran cantidad de libros rela-
cionados con la Biblia y todos en francés como El Geremías, Obras de Isaías, Los cionados con la Biblia y todos en francés como El Geremías, Obras de Ysá́as, Los Macabeos, Los Doce Pequeños Profetas y varios Salmos de David uno de ellos tra-
ducido de la lengua hebrea a la latina por Benito Arias Montano, el responsable de la publicacion de la Biblia Políglota.

Las hagiografias o vidas de santos ocupan poco espacio, tiene una Vida de San Bernardo, una Vida de San Francisco Javier en inglés y la Vida de Santa María de la Cabeza

Posee también Constituciones y Definiciones de Ordenes Religiosas como la del Toyson d'oro, orden a la que pertenecía el marqués, las de la Orden de Santiago las del Collar de Oro, las de la Compañía de Jesús y las de la Orden de Calatrava, orden a la que él mismo perteneció. Una obra curiosa para este tiempo es una Orden de los franc-masones de Pérau en francés; el interés estriba en que el P. Rávago, confesor de Fernando VI, había influido ya en que se dictara la primera orden antimasónica, a pesar de que en España todavía no había seguidores. ${ }^{32}$

Campomanes es aparentemente el personaje más laico de los tres, pero sólo si tenemos en cuenta los porcentajes, en este caso verdaderamente engañosos; un $7,8 \%$ de sus libros son de temática religiosa, pero son 366 volúmenes, es decir, más de un centenar más que Ordeñana Si tenemos en cuenta que el siguiente tema en orden ascendente son las Bellas Letras y tiene 906 volúmenes, notaremos mejor escasa representación porcentual de los libros de materia religiosa. La Teología parece interesar también muy poco a Campomanes y los libros que posee se refieren más a obras de doctrina o de moral cristiana, de disciplina y ritos de Iglesia primit-

32. LEGUINA, E., El padre Rávago, confesor de Fernando VI, Madrid, 1876, pp. $45-66$. 
va lo mismo que libros de devoción, vidas de santos y catecismos. Campomanes tenía la Vulgata y la Biblia en hebreo y en griego, en latín, en alemán y una traducción en español.

Pero también poseía obras de San Agustín, San Anastasio de Alejandría,Tertuliano o San Juan Crisóstomo. Obras de teología escolástica de pura ortodoxia doctrinal u otras galicanas o jansenizantes.

VARIOS

Se trata principalmente de Almanaques, Diccionarios Portátiles y óperas. Ni Ensenada ni Campomanes tenían nada de esto por lo que trataremos solo a Ordeñana.

Muchos son los Almanaques que poseía, algunos son franceses y otros castellanos. El Almanaque se puso muy de moda en la primera mitad del siglo XVIII y tenían un gran componente astrológico; era una suma de pronósticos que luego se fueron haciendo más racionales y pasaron a ser simplemente informativos. Estos almanaques y pronósticos forman parte de la "literatura" más económica del momento y su publicación era un éxito seguro. El autor más conocido e importante fue Diego Torres y Villarroel el "Piscator de Salamanca". Ordeñana tiene sus pronósticos para el año 1754 y los de su sobrino Isidoro Ortiz Gallardo Villarroel para el mismo año; ambos fueron Catedráticos de Matemáticas en la Universidad de Salamanca.

Ordeñana cuenta con un Memorial en defensa de las mugeres de España, y de los vestidos y adornos que usan de Arias Gonzalo. La mujer en el siglo XVIII sale del ostracismo de los Austrias para pasar a jugar un importante papel en el mundo cortesano borbónico. Dentro de esta nueva sociedad que se está formando surgen damas ilustradas que presiden importantes tertulias como la Condesa de Lemos o la de Benavente, otras llevaron las riendas del poder como la Princesa de los Ursinos. De la mujer austera austríaca se pasa a esa otra mujer ataviada de los lujos parisinos muchas veces criticadas por sectores conservadores pero también hay quienes las defienden como ocurre con este memorial por lo que puedan ayudar en la economía del país.

LAS BIBLIOTECAS Y SUS IDIOMAS

Para el estudio de los idiomas de los libros en el caso de Ordeñana nos hemos servido del $72 \%$ del total, de Campomanes del $83 \%$ y de Ensenada del $63 \%$. Los resultados han sido los siguientes:

Tabla 5. Las bibliotecas y sus idiomas

$\begin{array}{ccc}\text { ORDENANA } & \text { ENSENADA } & \text { CAMPOMANES } \\ 45,61 \% & 46,7 \% & 50 \% \\ 42,44 \% & 46 \% & 11,75 \% \\ 6,78 \% & 3,2 \% & 31,67 \% \\ 3,71 \% & 3,2 \% & 4,34 \% \\ 0,54 \% & 1 \text { libro } & 1,4 \% \\ 0,72 \% & 1 \text { libro } & 0,24 \% \\ 0 & & 0,2 \% \\ 0 & 1 \text { Libro } & \end{array}$


El francés fue el idioma de las cortes y los medios cultivados de Europa. La primera mitad del siglo XVIII español tuvo en la corte un verdadero dominio del francés, a pesar de la xenofobia antifrancesa del pueblo. ${ }^{33}$ Los cortesanos debían hablar francés. Ensenada lo aprendería cuando estuvo acompañando al infante y velando por la alianza hispanofrancesa en beneficio de instalar a su "amo"; igual haría Ordeñana, pero éste además debió estudiarlo (a juzgar por el número de gramáticas que poseía). Es muy notable en este sentido que Campomanes tenga menos volúmenes en esa lengua. El primer borbón español impuso el francés en la corte y los lazos con Francia eran muy fuertes, pero ya con Fernado VI, el primer monarca nacido aquí, se asiste a una "españolización" ${ }^{34}$ bastante evidente y además querida entonces; con todo, no hay que olvidar que en Francia se están produciendo las obras de mayor interés intelectual.

Desde 1714 el francés sustituyó al latín en las negociaciones y en los tratados. El latín se conservó en círculos cultivados, cada vez más clericales, y fue quedando reducido a la versión de obras clásicas o religiosas. Campomanes posee el 31,67\% de sus libros en este idioma debido a que la mayoría de sus libros de Derecho estaban en latín y a que había tenido una sólida formación universitaria. En las Bibliotecas de Ensenada y Ordeñana representa un 3,2\% y un 6,78\%.

El Italiano pierde peso en las tres bibliotecas, Ensenada tiene 17 volúmenes en este idioma y Ordeñana 41. El italiano es un idioma que va perdiendo protagonismo -aún cuando, en la corte de Fernando VI haya una cierta euforia "italiana" arrastrada por los músicos- pero es curioso observar cómo la gran mayoría de los libros en italiano se refieren a temas de Historia y Geografia.

Ensenada tiene 1 libro en inglés y son unas Ordenanzas de Marina, Ordeñana tan sólo tiene 8 volúmenes pero las gramáticas y diccionarios muestran su interés por aprenderlo. En el siglo XVIII los hombres cultos del momento se jactaban de saber inglés y Ordeñana no podía ser menos. El número de volúmenes en inglés de Campomanes es reducido y mostraba dificultades para entenderlo.

El Portugués está escasamente representado en las tres bibliotecas; Ensenada no tiene ninguno; Ordeñana tan solo 6 volúmenes y Campomanes 74 volúmenes. El portugués es un idioma relativamente sencillo para unos políglotas como Ordeñana y Campomanes y no debió ser despreciable desde que la reina Bárbara era una portuguesa y sus sirvientes influyeron bastante en algunos momentos.

Campomanes es el único que tiene libros en catalán y griego. Los libros en Catalán son 14 volúmenes y en griego solo tiene uno. Este dato es muy importante porque hay quien ha definido a Campomanes como "un helenista en el poder" 35 cuando solo tiene un libro en este idioma. No creemos que Campomanes supiera mucho griego porque uno de los lugares donde uno demuestra el dominio de un idioma es en su biblioteca, un único libro en una lengua no da pie a pensar que Campomanes supiera griego como se ha dicho.

33. EGIDO,T., Opinión...

34. GÓMEZ MOLLEDA, M.D., "viejo y nuevo estilo..."

35. GIL, L., Campomanes, un helenista en el poder. Madrid, 1976 


\section{CONCLUSIONES}

Una biblioteca como la que poseía Ordeñana en 1754 nos pone en contacto con un hombre de sólida formación cultural, relacionado con las novedades europeas, claramente en la línea del influjo francés característico del siglo.Tanto él como su patrón adoran la política estatalizadora y el impulso de la cultura producidos en el reinado de Luis XIV.A pesar del recelo que despiertan las costumbres francesas, como tuvo ocasión de observar el embajador Duras ${ }^{36}$, sobretodo en algunas "impiedades" o frivolidades que emanaban de la corte de los luises -ya veremos en la correspondencia Feijoo-Ordeñana la opinión del célebre fraile-, Ordeñana y Ensenada no demuestran temor alguno al defender un afrancesamiento que todavía no despertaba grandes hostilidades en materia moral y política. No sólo el número de libros en francés sino el poseer obras de Voltaire, Rousseau, los dos tomos ya aparecidos de la Enciclopedia, y otras de importancia política capital que llegaban a España en esa lengua -Puffendorf, Grocio, etc.- demuestra su interés por lo que está pasando al otro lado del Pirineo.

Ordeñana, como creatura y fiel de Ensenada, se sitúa claramente en el lado de la Ilustración de saberes prácticos, aunque, sin duda mejor formado que su patrón, podría ser su "brazo ilustrado" en las letras y la crítica, el hombre de los fundamentos y la reflexión. Ensenada, que oía más que leía, le tenía cerca a él y a tantos otros para escuchar con deleite toda novedad. Un hombre que como Ordeñana se carteaba con Feijoo debió agradarle tanto como un dicharrachero padre Isla, compañero constante. Para los saberes empiricos ya tenía a Jorge Juan y a Ulloa, para la inteligencia comercial al sagaz y emprendedor Fernández de Isla; para estar enterado de los chismes italianos, al padre Mogrovejo; en fin, para conocer lo que se movía por toda Europa en torno a novedades de todo tipo, a la red de embajadores con quienes se carteaba, a veces montando una correspondencia paralela a la oficial que llevaba el jefe de la diplomacia, Carvajal.También gozó siempre, por él o a través de Ordeñana y los suyos, de buenas relaciones con otros sabios de la época como Mayans, el padre Sarmiento, Luzán, el desgraciado Macanaz, y con los embajadores extranjeros en Madrid.

Muchos de los libros de la biblioteca de Ordeñana, difíciles de encontrar no sólo por estar prohibidos, encontrarían en esta red de élite un fácil canal para pasar las fronteras. Alguna vez en la correspondencia de Ensenada o de Carvajal se lee la petición de un libro a un embajador extranjero, por ejemplo la Enciclopedia, el Tratado de agricultura de Jethro Tull, etc.

En cualquier caso, lo que descubre la biblioteca de Ordeñana es el perfil de un hombre de conocimientos amplios, que traspasan las barreras de una España atrasada y dependiente, bien que agigantadas por quienes han puesto los Pirineos mucho más altos de lo que luego lo fueron. 


\section{BIBLIOGRAFÍA}

\section{AAVV. 1984}

Libros, libreros y lectores: Revista de Historia Moderna 4. Anales de la Universidad de Alicante.

ABELLÁN, J.L. 1981

Historia crítica del pensamiento español. Del Barroco a la Ilustración. Madrid.

AGUILAR PIÑAL, F. 1981-1989

Bibliografía de autores españoles del siglo XVIII, tomos I a V. Madrid.

AGUILAR PIÑAL, F 1981

"Sobre política cultural de Fernando VI": La época de Fernando VI. Oviedo.

AGUILAR PIÑAL, F. 1994.

La Biblioteca de Jovellanos (1778). Madrid.

ALCARAZ GÓMEZ, J. F. 1995

Jesuitas y Reformismo. El Padre Francisco de Rávago (1747-1755). Valencia.

CASO GONZÁLEZ, J. M. 1988

"De ilustración y de ilustrados":Textos y estudios del siglo XVIII,. Oviedo.

CASTRO, C. 1996

Campomanes: estado y reformismo ilustrado. Madrid.

DEFOURNEAUX, M. 1973

Inquisición y censura de libros en la España del siglo XVIII. Madrid.

DEMERSON, P. 1976

Esbozo de Biblioteca de la Juventud Ilustrada (1740-1808). Oviedo.

DEMERSON, G. 1971

Un aspecto de las relaciones hispano-francesas en tiempos de Fernando VI: Las Memorias Literarias de Paría de Ignacio Luzan (1751). Lyon.

DOMÍNGUEZ ORTIZ,A. 1976

Sociedad y Estado en el siglo XVIII español. Barcelona.

EGIDO LÓPEZ,T. 1971

Opinión pública y oposición al poder en la España del siglo XVIII. Valladolid.

EGIDO LÓPEZ,T. 1973

Sátiras políticas de la España Moderna. Madrid.

ELORZA,A. 1990

La modernización política en España. Madrid.

FAYARD, J. 1982.

Los miembros del Consejo de Castilla. Madrid.

FERNÁNDEZ, R. 1993

Manual de Historia de España, vol 4, La España Moderna, siglo XVIII. Madrid.

FERNÁNDEZ ALBADALEJO, P. 1988.

Carlos III y la Ilustración. Madrid. 
FERNÁNDEZ-QUINTANILLA, P. 1981.

La mujer ilustrada en la España del siglo XVIII. Madrid.

GÓMEZ RUIZ, M. 1991

El ejército de los Borbones. Madrid.

GÓMEZ URDÁÑEZ, J.L. 1996

El proyecto reformista de Ensenada. Lleida.

GÓMEZ URDÁÑEZ, J.L. 1995

"El Proyecto político ensenadista en la polémica sobre el el Despotismo Ilustrado en España". Notas sobre el proyecto de investigación "Ensenada 2002": Brocar 19, pp. 85-129. Logroño.

GÓMEZ URDÁÑEZJ.L. y LORENZO CADARSO, P. 1993

"Las comunidades rurales frente al Estado Absoluto": Mélanges de la Casa de Velázquez, XXIX. Madrid.

HERR,R. 1964.

España y la Revolución del siglo XVIII. Madrid.

LAMARGA LANGA, G. 1994

La cultura del libro en la época de la Ilustración. Valencia.

LAFARGA, F. 1982

Voltaire en España (1734-1835). Barcelona.

LÓPEZ PIÑERO, J. M. 1969

La Introducción de la Ciencia Moderna en España.Valencia.

MARTÍN GAITE, C. 1970

El proceso Macanaz, Historia de un enpapelamiento. Madrid.

MARTÍNEZ SHAW, C. 1996

El siglo de las luces. Las bases intelectuales del reformismo. Madrid.

MESTRE,A. 1976

Despotismo e Ilustración en España.Valencia.

MESTRE,A. 1990

Mayans y la España de la Ilustración. Madrid.

MORALES MOYA,A. 1987

Reflexiones sobre el Estado Español del siglo XVIII.Alcalá de Henares.

MUÑOZ MOLINA, S. 1977

Inquisición y Ciencia en la España Moderna. Madrid.

NAVARRO MALLEBRERA, R. y NAVARRO ESCOLANO,A. M. 1987

La Biblioteca de Jorge Juan. Alicante.

OZANAM, D. 1975.

La Diplomacia de Fernando VI. Madrid.

OLAECHEA, R. 1981

"Política Eclesiástica del Gobierno de Fernando VI":Textos y Estudios del siglo XVIII 9, pp 139-277. Oviedo. 
PALAU Y DULCET,A. 1971

Manual del librero Hispano Americano. Bibliografía general Española e hispanoamericana desde la invención de la imprenta hasta nuestros tiempos con el valor comercial de los impresos descritos. Barcelona.

PEÑA, M. 1996

Cataluña en el Renacimiento: libros y lenguas. Lleida.

RIBES, I. 1984

"Libros de Muratori traducidos al castellano": Revista de Historia Moderna.Alicante.

RODRÍGUEZ VILLA,A. 1878

Don Cenón de Somodevilla, Marqués de la Ensenada. Madrid.

SARRAILCH, J. 1974

La España Ilustrada de la segunda mitad del XVIII. Madrid.

SÁNCHEZ BALCO-PARODY, F. 1991

Europa y el pensamiento español del siglo XVIII. Madrid.

SOUBEYROUX, J. 1982

La Biblioteca de Campomanes: contexto cultural de un ilustrado. Roma.

TOUCHARD, J. 1983

Historia de las Ideas Políticas. Madrid. 
CRISTINA GONZÁLEZ CAIZÁN

\title{
LA BIBLIOTECA DE ORDEÑANA
}

\author{
Según el inVentario de 31 de Julo de 1754, ordenado por Wait. \\ AHN Estado Leg. 5040. Folios 45 a 53.
}

Transcripción paleográfica. Se respetan grafias y puntuación.

\section{Libreria}

-Treinta y seis tomos en quarto dela Historia eclesiastica por el Abad defleuri enquadernados enpasta, y Idioma franzes.

-Otros quatro tomos enquarto ystoria del antiguo y nuebo testamento, por don Agustín Calmet enquadernados en pasta, ydioma franzes.

-Otro tomo enquarto esposición dela doctrina xptiana por Monsieur Boujesan.

-Otros diez y siete tomos en quarto delas obras deBosuet enpasta.

-Otro en medio quarto pasta blanca, corneligansene sistema.

-Otro en octavo tratado de beneficios por sarpi en pasta.

-Otros dos tomos en octavo discurso sobre la Historia eclesiastica, por el Abad defleuri enquadernados en pasta.

-Dos tomos enquarto Rectimus disciplina, canonicorum en ydioma latino, su autor el Padre eusebio Amort enpasta.

-Otro en medio quarto nuebo sistema dela filosofia delos planetas, su autor el dho Padre Amort en ydioma latino.

-Otro en octavo, Hallucinaciones ar reberendisimo Patrem Virgili setilmair, en pasta y ydioma latino del dho Amort.

-Otro ygual ad responsionen apologetiam del mismo autor Amort.

-Otro Idea debine amorés delmismo autor.

-Otro sistema dotrine delpropio.

- Dos enquarto en pergamino en ydioma ytaliano dela Historia delprobabilísimo y del Rigorosísimo su autor el Padre Concina.

-Otro deafolio enpasta amort deyndulgencias.

-Otro enquarto con cubiertas depapel, lamenor pritani deyngeniorum moderacione.

- Otro enquarto amort derebelacionibus enpasta.

-Otros dos enquarto en Italiano muratori, perfecta poesia ytaliana en pasta.

-Otros dos enquarto enfranzes Historia del Concilio de trento. Su autor sarpi traducido por monsieur curayer enpasta.

-Otros tres tomos enquarto. Su autor el Padre Honoré reflexiones sobre la critica enpasta.

-Otro enpasta disertaciones singulares. Su autor don Pedro Benitez Cantos manuscrito.

-Otros quatro enquarto dicionario delaBiblia por Calmet enfranzes enquadernado en pasta.

-Un tomo marca mayor en pasta, narracion delas fiestas zelebradas en Napoles por el nacimiento del Principe Real de Sicilia en Italiano.

-Otro, un poco mayor que elantezedente, fiestas en París por el casamiento de Vrs. Infante don Phelipe. - Cinco tomos en folio explicación delabiblia en pasta quese dize traidos de la Librería Italiana dela Calle del Principe, y pareze pertenezen al mismo Librero.

- Otro demedio folio Zelebración delas Bodas del duque deSaboya con laSeñora da María Antonia fernanda en Italiano.

-Otro del mismo tamaño en pergamino deretratos dediferentes personas rs y otras.

- Otro delmismo tamaño antigua Romana por buenabentura oberbec.

-Otro enquarto descripcion dela fiesta en napoles por la Conquista del Reyno deSicilia por elseñor Rey dn Carlos en pasta.

-Otro enpasta blenca la crusca Provenzale debostero en quarto.

-Otro enquarto ypasta tablas deResucion sobre las medidas de Castilla por dn Phelipe Medrano.

-Otro enquarto demapas del Reyno desicilia enpasta.

-Otro en quarto ynstruciones delsanto oficio dela Inquísición enpergamíno. 
-Otro manuscrito enpasta, parecer quedio quedio el Padre Cano a Vrs Rey dn Phelipe Quarto sobre la Guerra de Napoles.

-Otro en octavo athomismo ynpugnado por el Padre Palanco en pasta.

-Otro deafolio biblioteca unibersal dela Apolografia su autor el Padre Rodriguez en pasta.

-Otro enquarto enpergamino la figura del pecador en portugues.

-Otro en quarto en pergamino reformacion xptiana por el Padre franco de Castro.

-Otros quatro tomos en pasta ynstrucion de un Principe $O$ tratado de las Calidades delas birtudes, y obligaciones deun soberano, ynpreso en Londres año demil setecientos y quarenta.

-Otros seis tomos en octavo en pasta el expestador o el socrates moderno sin nre deautor, traducido del yngles año desetecientos quarenta yuno.

-Otros diez y seis tomos en octavo enpasta, memorias de Rouset por el mismo.

-Otros diez y siete tomos tanbien en octavo, por el dicho Rouset yntereses delas potencias dela Auropa.

-Otro tomo en octavo, nuevas cartas familiares, y otras sobre todo género de asumptos Con su respuestas por villeran.

-Otros quatro tomos enquarto Genealogías ystoricas delos Reyes y imperadores detodas las Casas soberanas.

-Tres especies dequadernos, Tablas de las puertas dela europa con una yntroducion delafortificacion, Compuesta de ciento y nobentayquatro planes, de las Ciudades mas Considerables del mundo, aumentada con onze planes, por M. de fer Geografo des M. catholíca y del $r$ delfin.

-Otros dos tomos enpapel suplemento al cuerpo universal diplomatico deldro delas Jentes oystoria delos antiguos tratados por monsr. Berbeirac.

-Otro tomo tanbien enpapel sin autor enquarto Capitulaciones del emperador Carlos setimo.

-Otros cinco tomos enquarto tanbien enpapel la Geografía moderna natural Historica, y politica, por Abrahan Du-Boix Geografo.

-Quatro tomos en octavo en pasta lastaBiblia, tarducida en franzes por los theologos dela unibersidad de Lovaina.

-Otros dos tomos enpasta el autor en cifra de L. M. pensamientos delconde de Oxenstir.

-Otro tomo enpasta sin autor la politica del Canciller Bacon chanciller deInglaterra.

-Otro tomo enpasta tanbién sin autor, reflexiones sre. lamisericordia deDios.

-Otro tomo, reflexiones morale, sobre las obras de Dios en el orn. natural.

-Otro tomo en dorabo enpasta Con solacion delos pusilamines por el Abad Luis Blosio.

-Otros quatro tomos enpapel Historia del Imperio Otomano por el Principe de Moldabía demetrio cantimir en mil setecientos quarentay tres.

- Otros dos tomos tanbien enpapel Compendio dela antiguay nueba Geografia por Juan Hubner.

-Otro dos tomos enquarto enpasta blanca dela antiguedad dela Iglesia deespaña, por el Padre Cayetano Cenio en latin.

-Dos tomos en medio querto cubiertas depapel dela publica felicidad demuratori en italiano.

-Un tomo en octavo enpasta Manuel Lexio, o dicionario portatil enfranzes sin autor.

-Otro en octavo observación critica sobre cierto articulo Sin autor en Italiano y en pasta.

-Otro en quarto. Animadbersiones criticas del Padre Brifia enpasta.

-Otros tres en quartos respuesta delPadre Brifia, al Libro antezedente, en Italiano, y enpasta.

-Otro en octavo, el Mundo loco, preferido al mundo sabio sin autor enfranzes en pasta.

-Otro en octavo, los Caracteres delHombre, sin pasiones, sin autor en pasta, y Idioma franzes.

-Otro enquarto de Reichnographica, sin autor en pasta.

-Otro en octavo Recoleccion delos emblemas, o tablas delas ciencias, por Monsr. Baudoin en pasta.

-Otro en octavo el mundo Condenado, sin autor en pasta.

-Otro en octavo, lamoral de tacito por Amelot en pasta.

-Otro en dorabo enfranzes obras de Kempis añadidas por el el Abad de Bellibar en pasta.

-Otro en octavo en franzes, la Bella VVolpéna enpasta.

-Otros diez tomos en dorabo del Abate Belegat enfranzes y en pasta.

-Otro en octavo las delicias de la españa, en franzes, y pasta blanca, su autor, dn. Juan Albarez Colmenar.

-Otro tomo en octavo, con cubiertas de tripe azul, reflexiones curiosas, sobre la ciencia, y valor para

la Guerra por el Coronel Perochegui en castellano.

-Otro en dorabo franzes, memorial de Cronología Genealogía y Historia en pasta fina.

-Otro enquarto enpergamino Cartas Eruditas del Padre feijó en Castellano. 


\section{CRISTINA GONZALEZ CAIZAN}

-Doze piscatores detorres, y otros doze desu sobrino para elaño demil setecientos cinquentay quatro en papel.

-Un tomo en latín, Hipolitus redíbibus en pasta en dorabo.

-Otro enquarto enpergamino Juicios sazerdotes por el Padre Calatayud en Castellano.

-Otro en quarto Benegasi, fama, postuma, en Castellano yenpasta.

-Cinco tomos en octavo en pasta, ordenanzas militares, en castellano.

-Otro en dorabo, ydioma franzes. Almanakes del cuerpo de mercaderes de París en pasta.

-Otro en octavo.Almanach franzes para elaño decinquenta y quatro enpasta.

-Otro enfranzes, en dorabo, y pasta, mis pensamientos.

-Otro en octavo, ordenanzas delRey Luis treze defrancia en pasta.

-Seis Almanaques de francia enpasta.

-Un tomo en pasta en dorabo meditaciones delaMisa en Castellano.

-Otro en dorabo Cornelio, Lepos en latín, y enpasta.

-Otros dos tomos deafolio en franzes, vidas deVarones ylustres, por Amiot, enpasta blanca.

-Otro enquarto pasta blanca y en castellano, vida y birtudes de Vrs.dn. Juan de Ribera.

- Tres tomos en octavo en pasta Historia del establecimito dela Monarquia franzesa por Dubos.

-Quatro tomos enquarto enpasta delas obras desta. theresa.

-Otro enquarto, Historia Inperial su autor elCavallero mesia enpasta.

-Otros dos enquarto enpasta blanca Adarga Cathalana, su autor dn. franco. Xaxier de Garma.

- Un tomo en octavo enfranzes, lamuger doctor en pasta.

-Otro enquarto enpasta, difiniciones delorn. De Calatrava en Castellano.

-Otro enquarto grande nuebo dicionario español, y Ingles suautor Pedro Pineda enpasta.

-Otro enquarto grande en Ingles dicionario Ingles y español.

- Otro enquarto dicionario franzes y Latino su autor Jph Jouber enpasta.

- Otro enquarto dicionario Latino y franzes su autor Pedro Danecio enpasta.

-Otros dos enquarto dicionario Latino franzes sin autor enpasta.

-Otro enquarto defensorio dela religiosidad de los Cavalleros militares en castellano enquadernado enpergamino.

-Otro enquarto anales deflandes por Manuel Sueíro en castellano enpasta.

-Otro enquarto Castellano memorias dePhelipe de Comines enlamisma enquadernacion su autor dn.

Juan Bitrian.

-Otro enquarto Latino Igogrocio anales.

-Otro enquarto Guerras de francia, por Henrrique Catherino Davila.

-Otro enquarto Mariana Historia deespaña en Castellano.

-Otro enquarto Castellano fundacion y Hordenanzas del orn. del toyson en pasta.

-Otro enquarto yndize delas Constituciones del orden del Collar deoro en latin.

-Otro enquarto grande Sciencie heroica por Marco de Bulson enfranzes.

-Otro enquarto enpergamino el blason de los Armeros enfranzes.

- Veinte y quatro tomos en octavo en Castellano la corte santa.

-Otro en octavo franzes Historia santa.

-Otros quatro en octavo franzes Historia delas variaciones de las Iglesias protestantes.

-Otro en octavo, Historia de la vida denuestra señor Jesuchrispto enfranzes.

-Otros dos en octavo reglamentos Generales, para la abadia delatrapa en franzes.

-Otros quatro en octavo Historia delas variaciones delas Iglesias protestantes, enfranzes.

-Otros cinco en octavo del antiguo testamento.

-Otros cinco en octavo del mismo asumpto del antiguo testamanto.

-Otro en octavo franzes reglas deperfeccion.

- Otro en octavo franzes obras de Isaias.

-Otro en octavo franzes salmos deDavid.

-Otro en octavo en el mismo ydioma, los doze pequeños profetas.

-Otro en octavo libro delos Juezes enfranzes.

-Otro en octavo franzes los Machabeos.

-Otro en octavo franzes Jeremias.

-Otros dos en octavo franzes sermones sobre los ebangelios.

-Otro en octavo pensamientos injeniosos delos Padres dela Iglesia.

-Otros dos en octavo franzes política sacada dela esra. 
-Otros cinco enoctavo exercicios depiedad paratodos los domingos en franzes.

-Otro en octavo Salmos de David.

-Otro en octavo Latino oficios deSemana santa.

-Otros treinta y tres tomos en octavo grandes, el Genesis.

-Otro en dorabo reglas de las religiosas dela vivitacion en Castellano.

-Otro del mismo ydioma meditaciones delapasion denro señor Jesuchrispto.

-Otro en Castellano en octavo diario dexpno.

-Otro en octavo nueba Gramatica Ingle ayfranzesa.

-Otro en octavo franzes, gramatica ynglesa franzesa.

-Otro en octavo franzes La Jornada del xptiano.

-Catorce tomos enquarto enfranzes lasanta biblia.

-Otros ocho enquarto Hidioma franzes, Historia delas ordenes Monasticas.

-Otros dos enfolio pequeño en latín Nicolao Antonio Biblioteca Ispana.

-Otros seis en medio folio, dicionario dela lengua Castellana por la Academia española.

-Otros dos del mismo tamaño Biblioteca yspana del mismo Nicolao Anto.

-Otro siete deafolio, dicionario detrebur.

-Otros dos enquarto pequeños Gramatica española en Ingles.

-Otro Gramatica Inlesa en quarto pequeño.

-Otro Bocabulario español en Ingles enquarto pequeño.

-Otro en quarto dicionario español y franzes.

-Otros dos enquarto Monarchia Ebrea encastellano.

-Otro enquarto, vida desta. María dela Caveza.

-Otro enquarto dicionario Ingles y español.

-Otros quatro enmedio folio enpergamino sermones deBieira.

-Cinco tomos en octavo franzes opusculos del mro. Bosuet.

-Otros dos en octavo, ydioma franzes, discursos sobre la Istoria universal.

-Otros tres en octavo ydioma Castellano el pecadpr sin escura.

-Otro en octavo ydioma franzes oserbaciones ynportantes de latesis del Abad de Priades.

-Otros dos Castellanos en octavo el pecador sin escura.

-Otros dos en castellano en octavo Historia desuzesos memorables del mundo.

-Otro enquarto en ydioma Italiano antigua Roma.

-Otro en octavo exercicios espirituales delas religiosas dela vísitación.

-Otros dos franzeses en octavo. Historia delRey dePrusia.

-Otro en octavo ydioma franzes el toison deoro.

-Otro latino en dorabo oficio dela virgen.

- Otros dos enquarto dicionario deSobrino.

-Otros dos enquarto dicionario franzes y Ingles.

-Otros dos enquarto bocabulario ytaliano y Latino.

-Otros dos enquarto dicionario ytaliano y franzes.

-Otro en quarto dicionario Geografico.

-Otro enquarto Latino vida del Cardenal Zisneros.

-Otro enquarto grande thesaurus Geograficus ortensio.

-Otros tres tomos deafolio en latín dicionario delos caros dela Conciencia su autor Pontas.

-Otros dos en folio dicionario delaSagrada escriptura.

-Otros dos deafolio en franzes dicionario dela Biblia.

-Otros tres deafolio dicionario Geográfico.

-Otros dos delmismo tamaño dicionario economico.

-Otros dos del mismo tamaño dicionario delas ciencias enfranzes.

-Otro en octavo franzes dicionario portatil.

-Otro deafolio en franzes medallas de Luis el grande.

-Otro enfolio Poligrafia española.

-Otro enfolio obidio metamorphoseos.

-Tres tomos enquarto pequeño en castellano Ribadeneira, pasatiempo.

-Otros Catorce del mismo tamaño, obras dedn. diego de torres.

-Otro enquarto cueba desto. domingo.

-Otro enquarto exequias del R. Luis primero. 
-Otro enquarto exequias del Vsr. duque deParma.

-Otros dos Almanaques franzeses.

-Otro Garcia deNabegación enquarto.

-Otro enquarto manuscrito zenones famosos.

- Otros cinco en octavo Historia unibersal.

-Otros ocho en Castellano, yntrodución ala ystoria.

-Otros dos Quinto Curcio.

-Otros dos quintiliano.

-Otros seis rebolucion deungria enfranzes.

-Otros quatro Anales detacito.

-Otros dos endho Idioma, vida deIsabel Reyna deungria.

-Otros dos endho ydioma, la vida deoliberio chormbert.

-Otro Historia del Estauderato enfranzes.

-Otros endicho ydioma, Historia deParlamento de Inglaterra.

-Otros quatro en el mismo ydioma Roullin, Modo de estudiar.

-Otro en dorabo Castellano la libra de Gribilio.

-Otro delmismo tamaño la Monarquia deespaña en Italiano.

-Otro del mismo tamaño, ordenanzas del rey defrancia sobre Hospitales Militares.

-Treze tomos en octavo en ydioma franzes Rollín Historia antigua.

-Otros diez y seis Historia romana por Crebier.

-Otro Historia unibersal en latin en octavo.

-Dos tomos en quarto en castellano cartas edificantes.

-Otros dos en quarto croiset año xpno.

-Otro en octavo biblia sacra.

-Otros doze enquarto historia del Pueblo deDios.

-Otros seis del mismo tamaño vida dexpto.

-Otro en quarto enpasta, oficio dela virgen para las religiosas dela vivitacion.

-Otros treze enquarto Historia unibersal.

-Otros tres enquarto Rapín Historia de Inglaterra.

-Otros quatro en quarto Historia cibil denapoles.

-Otros ocho deafolio dicionario deMoreri.

-Otros quatro dedicho tamaño dicionario de bayle.

-Otros tres deldho tamaño dicionario de Comercio.

-Otro del dicho tamaño fr Jph desn Benito.

-Otros dos en octavo dicionario Historico portatil en franzes.

-Seis tomos deafolio Glosa de escriptores.

-Otros dos tomos deafolio Historia delos tratados depaz.

-Dos tomos en folio pequeños solis y salazar Historia deMexico.

-Otro en folio pequeño, García origen de los yndios.

-Otro del mismo tamaño theatro del honor en latin.

-Otro del mismo tamaño uztariz de Comercio y Marina.

-Otro del mismo tamaño elGobernador Christiano.

-Otros cinco delpropio tamaño Historia delas Indias por Herrera.

-Otro enquarto farmacopea Matritense.

-Otro enquarto Ruici opera.

-Otro delmismo tamaño Panel deZistofuris.

-Otro en octavo vida desn franco xavier en Ingles.

-Otros dos enquarto arte de la Guerra enfranzes.

-Otros dos delmismo tamaño Milicia franzesa.

-Otros dos en folio pequeño tratado desubsistencias militares.

-Otros cinco enquarto Historia de Polibio.

-Otro en octavo Mayans filosofia moral.

-Otros diez delmismo tamaño vida delos Hombres ylustres dePlutarco enfranzes.

-Otros quatro en octavo Historia delas bellas letras.

-Otros seis en octavo Istoria natural General y particular.

-Otros cuatro del mismo tamaño memorias dela europa en franzes. 
-Otro deafolio pequeño en pergamino, reglas y establecimientos del orn de santiago.

-Otros dos delmismo tamaño Historia de la religión desn Juan en pergamino.

-Otro del propio tamaño cronica delas ordenes militares en pergamino.

-Ocho tomos deafolio cuerpo unibersal, diplomatico.

-Otros cinco del mismo tamaño suplemento al mismo Cuerpo diplomatico.

-Otros dos delpropio tamaño Paz deMuster.

-Nuebe tomos enquarto Historia General delas viajes.

-Otro enquarto oserbaciones Astronomicas y fisicas.

-Otro enquarto Bouguer figura delatierra.

-Otros quatro en quarto Relacion del viaje alamerica.

-Otros dos Ulloa viaje a la America del mismo tamaño.

-Otro del propio tamaño tratado General de Comercio.

-Otro viaje de Ganron del mismo tamaño.

-Otro Aneon viaje, del mismo tamaño.

-Otros dos Historia dela Marina enquarto.

-Otros dos enquarto pequeño Bonamici deVelo Italico.

-Otro en octavo deBelo rustico valentino por Mayans.

-Otro en Ingles en octavo seignora dequetrata.

-Otro en octavo de Rebus Gestis eugeny en octavo.

-Nuebe tomos en octavo en franzes espectaculo dela naturaleza.

-Otros quatro en octavo Nollet de fisica.

-Otros quatro enel mismo tamaño entretenimiento fisico.

-Otros dos en octavo la Logica.

-Otro en octavo comentario sobre latraducion enberso del Abad de Reisnet.

-Otro conocimiento del espiritu Humano.

-Otros dos examen del espiritu enel mismo tamaño.

-Otros tres entretenimientos mathematicos.

-Otros dos tratado del berdadero merito del Hombre.

-Otros quatro caracteres de teofrasto.

-Otro enoctavo grande ensayo sobre la electricidad delos cuerpos.

-Otros dos en octavo en ytaliano Istoria de Carlos doze.

-Otro tomo del mismo tamaño modo de Juzgar bien.

-Otros dos en octavo Historia delcielo.

-Otros dos en octavo el siglo de Luis catorce.

-Otro enquarto pequeño theorica delafigura dela tierra.

-Otro tomo theres de lafilosofia Jesuita.

-Otros ocho tomos en octavo, v viajes Historicos atodas las cortes de europa.

-Otros quatro en octavo viaje deAnson.

-Otros dos viajes del mar de Usuz en octavo.

-Otro en octavo, viajes deZiro.

-Otros dos viaje de Grodinat en yngles.

-Otros cinco en octavo Historia del Principe eugenio de saboya.

-Otros dos en octavo Comentario deZerar.

-Otros dos Historia del Cardenal Ximenez del mismo tamaño.

-Otros tres la emperatriz Romana en ytaliano del mismo tamaño.

-Otros diez delpropio tamaño biblioteca deCampana.

-Otro Paralelo del Cardenal Roserier.

-Otro Consideraciones sobre las causas delas Grandeza delos Romanos.

- Otros dos Cartas sre la ystoria de Bolingroch.

-Otros dos en octavo Pancorbo.

-Otros dos, compendio dela Historia deespaña tanbien en octavo.

-Otro dicionario dela fabula.

-Otro flos latinitatís del mismo tamaño.

-Otro paralelo del Cardenal Ximenez y Rusileu.

-Otro Memorias depersia.

-Otros dos curiosidad dela Naturaleza, y delarte del mismo tamaño. 
-Otro la nobedad de Democrito.

-Otro nabegación desanchez.

-Otro la Ramandi, Historia dela Cantabria.

-Otros quatro enpasta blanca, obras deBulifont en Italiano.

-Otro enquarto tratado demonedas.

-Otro arte dememoría.

-Otros seis en octavo, memorias delas ciencias.

-Otro Luzan memorias literarias.

-Ocho tomos en octavo espetaculo dela naturaleza.

-Otros diez tomos en octavo, Geografia ystorica del Pe Murillo.

-Otros dos Historia del duque deAlba en medio quarto.

-Cinco Almanaques franzeses enquarto.

-Dos tomos enquarto fiquet medicina, y Zirújía.

-Otro enquarto, obras de Cayo Cornelio tacito.

-Otro memorias para la Historia dePhelipe tercero en quarto tanbién.

-Otro enquarto, ynpugnayn contra eltazmuz delos Judios.

-Otro Guerra entreferdinando segundo y Bustabo adorfo.

-Otros dos controbersias ylustres enpergamino.

-Otros quatro tomos enquarto, Architecturay draurica.

-Otros quatro Moral moralizado enquarto.

-Otro tomo beda cronica delos moros.

-Otro Hernandez thesauro de plantas.

-Otros dos Pereira, obras medicas.

-Otros dos dicionario trilingue.

-Otros dos examen delos escritores valencianos.

-Otros dos enpergamino corona Rl de los Pirineos.

-Tres tomos, obras deVirgilio.

-Otros dos obras de Lucrecio.

-Otros ocho, oracio.

-Otros seis theatro delos Griegos.

-Otros dos la dona pohema.

-Otro Viaje delParnaso.

-Otros dos lapractica detheatro.

-Otro demostrayn del Principe dela Armona.

-Otro virginia trajedia.

-Otro Ataulfo trajedia.

-Otro francisci sanci enblema.

-Otros dos examen de Machiabelo.

-Otros seis de Justo lisio.

-Otro Bosuet recolecion istorica.

-Otros dos aberbiacion dela milicia defrancia.

-Otros tres, dicionario militar.

-Otro dicionario Geografico.

-Otro dicionario militar.

-Otros tres Codigo defederico.

-Otros quatro tratados depares.

-Otro Considerayn sobre el Comercio de Inglaterra.

-Otros dos, anedoctos ystoricas.

-Otros dos principios del dro político.

-Otro oya leyes penales.

-Otros dos, principios deldro natural.

-Otro dos eldro publico Germanico.

-Otros quatro el espiritu delas leyes.

-Otro defensa delas leyes.

-Otros dos Codigo Rural.

-Otro arte depicadero. 
-Otros dos codigo deViajar.

-Otros cinco codigo militar.

-Otros dos, reflexiones políticas.

-Otro Consideraciones, sobre el Comercio delagran bretaña.

-Otro Comercio deolanda.

-Otros dos derecho publico.

-Otros dos examan de comercio.

-Otro ordenanzas de Guardias deynfanteria.

-Otro Ordenanzas demarina.

-Otro testamento politico deReselier.

-Otro ynstituciones españolas detorres.

-Otro Ordenanzas dela Compa deestremadura.

-Otro reglamento general del Rey pa los reximientos de Guardias franzesas.

-Otros quatro detalles militares.

-Otro ordenanzas de Luis Catorce.

-Otro edicto del rey sobre reglamento de ynpresores.

-Otro laJusticia militar.

-Otro ynstrucion deprosero berbal.

-Otro en octavo grande questiones deldro publico.

-Otro tratado de lebas.

-Otro Arcanorum estaus de pufendort.

-Otro obligaciones del Hombre.

-Otro obras menores deBanbrinques.

-Diez y ocho tomos en octavo, causas zelebres.

-Otro memorias tocantes a los embajadores.

-Otro tratado del oficio competente delos embajadores.

-Otro tratado Jurídico sre presas demar.

-Otro origen delarenta del servicio y montazgo.

-Otro Comentario sobre las tarifas.

-Otro tratado ystorico del Comercio deIndias.

-Otro proyecto Real.

-Otros seis en quarto Recolecion delos tratados depaz.

-Otros dos tomos derechos dela naturaleza, y de las Jentes.

-Otros dos derechos dela Guerra.

-Otros dos los embajadores, y sus funciones.

-Otro, memorias sobre asientos y preferencias entre los soberanos.

-Otro el embajador politico xptiano.

-Otros dos Valiente, aparato deldro publico.

-Otro tratado filosofico delas leyes naturales enfranzes.

-Otro tratado de Jurisprudencia demuratori.

-Otro recoleccion delos decretos ydeclaraciones defrancia.

-Otros dos tomos esciencia perfecta delos notarios.

-Otros dos practica cibil y criminal.

-Otro restaurayn política de españa.

-Otro estatuto y reglamento delHospital general.

-Otros doze tomos deafolio tratado depares.

-Otros quatro deafolio recpilacion de las partidas de Gregorio Lopez.

-Otros dos politica deBobadilla.

-Otro tomo enquarto pinpido ysidoro.

-Otro defensa canonica sre pertenecer ala Corona la Abadia de Hermedes.

-Otro devarios planes y figuras.

-Otros dos en octavo, conduta delsabio.

-Otros dos fabulas delas Abejas.

- Otros dos en octavo, vida dedn Quijote.

- Otro nueva y perfecta gramatica franzesa.

-Otro Enielio armonia de las lenguas. 
-Otro gramatica francesa de Bufier.

-Otros quatro tomos, recoleyn detestementos.

-Otro restaut abrebiación delos principios dela Gramatica francesa.

-Otros tres enquarto grande obras desaabedra.

-Otro obras delprincipe esquilache.

-Otro el arte de bersificar laidavas.

-Otro obras deVirgilio.

-Otro recoleccion deantiguedades.

-Otro ensayo del Alfabeto delas letras, no conocidas.

-Otros dos casa Rustica.

-Otros dos berdadero methobo deestudiar.

-Otro eszelencias deespaña.

-Otro marco Antonio Retorica deAristotilis.

-Otro enquarto Constantino el grande.

-Otro Palacio dela eloquencia.

-Otro filosofia deAmort.

-Otro prospero defortificación.

-Otros ocho enquarto grande las obras filosoficas deBolfio.

-Otros quatro los caracteres de las pasiones.

-Otro filosofica dexptiano.

-Otro física moderna racional.

-Otros quatro enfolio nuevo tesauro delderecho cibil yCanonico.

-Otros dos obras deUbaspen.

-Otro en octavo ordenanzas del Hospital deobiedo.

-Treze tomos en octavo grande delas obras del Padre feixó.

-Otros tres tomos theatro antecritico universal de Maníez y sarmiento sre dhas obras del Padre feijó.

-Otros dos examen dela crisis del Padre feijó, por el padre dn Antonio Reymundo.

-Otros dos obras degracián.

-Otros cinco obras de Quebedo.

-Otros tres en dorabo, obras deRoseau.

-Ocho tomos del mismo tamaño, obras de Moliere.

-Otros tres obras deRacino.

-Otro La poteosia del buen sexro.

-Otro Istoria, y abentura deGabriel Marquisi.

-Otro lista general delas postas defrancia.

-Otro dibersas de sieux.

-Otros dos obras Historicas y políticas del Marqus desnJil.

-Otro practica demaniobras.

-Otro La aropedia.

-Otro Istoria detecli.

-Otro estilo denobles pensamientos.

-Otro tabal Genealogica delos Papas.

- Otro el Diablo cojo.

-Otro dela manera de negociar los soberanos.

-Otros dos Ordenanzas de Luis Catorce.

-Otros dos memorias dela España.

-Otros tres Historia Genealogica delos papas.

-Otro almanac delaño.

-Otro Zizeron en dorabo.

-Otro prontuario delConsejo de Guerra.

-Otro selecta Istoria delos escritores profanos y sagrados.

-Otro obras postumas dedn felix Arteaga.

-Otro educacion dela Jubentud.

-Otros dos los Majistrados y tribunales deespaña.

-Otros siete en octavo obras de Cornelio.

-Otros cinco poemas de cornelio. 
-Otros quatro Biblioteca poetica.

-Otros tres reflexiones sre lapoeesia.

-Otro elparaiso perdido.

-Otros tres dicionario de mitologia.

-Otro Arte de la tintura.

-Otro Arte deAprender el arte medica.

-Otro, Poesias de Boltaire.

-Otros quatro, obras de Nicolas Boileau.

-Otros dos Cartas aun Americano.

-Otro los Maestros escolares.

-Otro Apologia delas mugeres.

-Otro uniberso abrebiado.

-Otro athalia trajedia de Racine.

-Otros dos las bellas soledades.

-Otro Georgicas deVirgilio.

-Otro Almenac y calendario diario.

-Otros dos tratado dela cultura delas tierras.

-Otro tratado dela conserbayn degranos.

-Otro fisica electrica de Nabarro.

-Otros dos tratado deCultura detierras.

-Otros discurso delConde de Busi.

-Otro Cartas dedn. Nicolas Antonio deSolis.

-Otro problemas yngleses.

-Otros siete tratado dela opinion.

-Otros tres la Geometria, theorica y practica.

-Otro la Architectura practica.

-Otro tratado dePuentes.

-Otros tres, elementos dequímica.

-Otro ensayo sobre la Architectura.

-Otro tratado dela Idrofobía.

-Otro virtudes del agua de Gudron.

-Otros dos regla artificial del tiempo.

-Otro ensayo de cosmologia.

- Otro Cultura de Jardines.

-Otro arte delaPintura.

-Otro en octavo grande uso del Compas deproporcion.

-Otro oserbaciones de cirujías.

- Otros dos curso militar de mathematicas.

-Otro ynstrucion dePrincipes y Reyes.

-Otro Armonica vida desta theresa de Jesus.

-Otro arte deurtar.

-Otros seis en quarto, presas dela Academia delas ciencias.

-Otros tres transacciones filosoficas dela sociedad deLondres.

- Otros dos ensayo defísica.

-Otros dos curso defisica.

- Otros dos elementos defisica.

- Otro elementos deGeometria.

- Otro elarte delaBerrerie.

- Otro ensayo deminas.

-Otro ensayo sobre el Hombre.

- Otros seis filosophía del entendimiento.

- Otro mas pequeño delomismo.

- Otro indize delafilosofia moral.

- Otro arte dela obtica.

- Otro elsecretario delRey.

- Otro cultibo delas tierras. 
-Otro deafolio marca de Concordia.

-Otros tres deafolio nueba Recopilación.

-Otro deafolio pequeño villa diego fuero Juzgo.

-Otro fuero real de españa del mismo tamaño.

-Otro Leyes dela mesta del mismo tamaño.

-Otro del mismo tamaño ontalba Jurisdicion del R1 Patronato.

-Otro Letras de Cambio Dominguez deafolio pequeño.

-Otros dos del mismo autor a la curia filipica.

-Otro practica deVentas.

-Otro salzedo de Contrabando.

-Otro Ordenanzas del Consejo delas Indias.

-Otros quatro Recopilacion de las Indias.

-Otros dos de solorzano.

-Dos tomos primero y segundo en octavo en castellano su titulo Ordenanzas militares echas deorn des $\mathbf{M}$ el año demil setecientos veinte yocho para el eximen, disciplina subordinacion y serbicio dela Infanteria, Caballeria y Dragones del exercito, en Guarnicion y en Campaña.

-Otro Libro en octavo su titulo instruciones y ordenanzas delo que deben practicar en elexercicio y serbicio desus empleos los comisarios ordenadores y de Guerra del exercito echo deorn des M. año demil setecientos quarentay ocho.

-Otro en octavo su titulo recopilacion delos reglamentos y ordenanzas del Rey para el serbicio exercicio disciplina, paga mando y Subordinacion delas compañias de Guardias de Corps y de Alabarderos y delos reximientos de Guardias hecho de orn des $M$. desde veintey nuebe deseptre demil setecientos y quatro asta Marzo demil setecientos veinte y quatro.

-Otro en octavo su titulo ordenanzas eynstruciones para el serbicio y gobierno delos empleos de comisarios de Guardias de Corps eynfantería española y VValona hecho de orn des M el año de setecientos quarentay ocho.

-Otro en octavo su titulo Rs ordenanzas demilicias con la recopilacion delas ordenanzas, Adiciones declaraciones ynstruciones y probidencias Generales expedidas para laformación delos treinta y tres reximientos demilicias hecho desde treintay uno de enero desetecientos treintay quatro asta veinte y ocho deAbril demil setecientos treinta y cinco.

-Otro en octavo su titulo reglamentos dePresidios expedido pors M. en primero de enero demil setecientos quarentey seis.

-Otro en octavo su titulo vida dethomas Kaulikan ynpreso año demil setecientos quarentey uno.

-Otro en octavo con primeray segunda parte su titulo prontuario de los tratos depaz de españa en el reynado de Phelipe tercero parte prima y segunda ympreso año demil setecientos treinta ynuebe.

-Otro en octavo su titulo obras de Casto Velleyo Paterculo traducidas delatin por Manuel Sueiro ympreso año demil setecientos y treinta.

-Otro su titulo en octavo primera segunda y tercera pte prontuario de los tratados dePaz deespaña reynado de Phelipe Quarto.

-Otro en octavo su titulo de Manuel de Grandes su autor Sebastian Querini ympreso año demil setecientos y quarenta.

-Otro en octavo su titulo conpendio y resolucion delas dudas que pueden ofrezerse en el brebe conzedido por la santa de ynnocencio decimo enque da facultad alos militares que sirben al Rey deespaña para Comer Carne el quaresma y otros dias aexzepcion delos reservados en laBulla ympreso año demil setecientos treintay tres.

-Otro en octavo su titulo estado politico dela europa tomo treze su autor dn franco Ignacio deortega. -Otro en octavo sutitulo coleccion detodos los escritos publicos en olanda en pro y encontra despues dela entrada delas tropas franzesas en el territorio delarepublica.

-Otro en octavo su titulo vida deelio sayano, traducido de franzes por vicencio sparciniafico ympreso año de mil setecientos veintey uno.

-Otro su titulo arte denegociar con los soberanos traducido delfranzes por dn Jph deAbreu ympreso año demil setecientos quarentay uno.

-Otro en octavo sutitulo Historia delas oredenes militares su autor franco Menini ympreso año demil seiscientos y treze.

-Otro en octavo sutitulo fastos dela Academia Rl española, ympreso año demil setecientos treintaynuebe. 
- Otro en octavo su titulo vida del duque de Riperda traducido delfranzes al castellano por Monsr le Margre ympreso año demil setecientos y quarenta.

-Otro enoctavo su titulo Guerra deGranada hecha por el Rey deespaña dn Phelipe segundo su autor dn Diego deMendoza ympreso año demil setecientos y treinta.

-Un Libro enquarto su titulo Historia General dela America septentrional su autor Lorenzo Boturini, ympreso año demil setecientos treintay seis.

-Otro enquarto su titulo viaje Rl del rey nro Sr dn Phelipe Quinto su autor dn Pablo Montes encio, ympreso año de mil setecientos veinte y uno, digo doze.

-Otros siete tomos enquarto su titulo diario delos literatos deespaña Compuesto por dn franco Huerta, dnJuan de solafranca y dn Leopoldo Puig ympreso año demil setecientos treinta y siete.

-Otro enquarto derecho deespaña almilanes ympreso año demil setecientos quarentay dos, traducido al castellano, por dn Miguel Joseph deAoiz.

-Un Libro enquarto derecho deespaña alos estados hereditarios dela Casa deAustria ympreso año demil setecientos treintay dos.

-Un Librito en octavo en latín sutitulo Grotius de Maria Libero, ympreso año demil setecientos treintay tres.

-Otro enquarto su titulo frax cronologico Adonifenani Historiam su autor el Pe Juan dominico Musancio Jesuita ympreso año de mil setecientos y uno.

-Otro enquarto su titulo seldini dedominio maris.

-Un tomo en octavo su titulo Istoria secreta deHenrrique quarto Rey de Castilla ympreso año de mil seiscientos y nobentay seis.

-Otro en octavo sutitulo Genealogia delos Grandes de españa su autor Jorge Hermont ynpreso año demil setecientos y siete.

-Un Librito en octavo en ytaliano sumario Istorico que contiene elestado del mundo.

-Otro en octavo su titulo la rebolucion deNapoles, suautor Alejandro Guirafi ympreso año demil setecientos diez yocho.

-Otro en octavo su titulo floresta yluminada dela Ciud deBenecia ympreso año demil setecientos y treinta.

-Un Libro en octavo su titulo compendio cronologico delaHistoria deeste siglo. su autor dn salbador don Jph Mañer ympreso año demil setecientos quarentay uno.

-Otro en octavo su titulo obras deCayo xpto sulustio por Manuel Surio ympreso año demilseiscientos y quince.

-Un Libro enquarto su titulo Imperio dela china y cultura evangelica en el porlos religiosos delaCompañía de Jesus su autor el Padre Albaro semmedi Jesuita ynpreso año de mil seiscientos quarentay dos.

- Otros dos en quarto su titulo el orinoco Ilustrado ydefendido Historia natural cibil y Geogrefica deste gran Rio Goberno uso y costumbres delos Indios su autor el Padre Joseph Gumilla dela Compañia de Jesus año demil setecientos quarentay cinco.

-Otro en quarto su titulo adbertencias Historicas sobre las obras dealgunos doctos escriptores modernos su autor dn Luis desalazar y Cardenas, ympreso año demil seiscientos ochenta y ocho.

-Otros dos tomos, primero, segundo y tercero en quarto. su titulo Historia Romana traducidos delfranzes al español por el Padre Mro Juan deAller, clerigo menor ympreso año demil setecientos treinta $\mathrm{y}$ cinco.

- Otros dos tomos enquarto su titulo Comentarios dela Guerra deespaña eystoria desu Rey dn Phe Quinto el animoso, desde principio de su reinado asta lapaz gral delaño demil setecientos veinte ycinco su autor el Marques desn Phelipe.

- Otros dos tomos enquarto, heras, y fechas deespaña, su autor el Pe Mro fr Pablo Jañes Iterciense, ympreso año demil setecientos treintay dos.

- Otro enquarto su titulo Diazcano,Vindicado apologia dela notoria lealtad dedon franco diaz Cano. Su autro el Padre Pedro Cano, dominico, Impreso año demil setecientos y quarenta.

- Un Libro en quarto en latín su titulo rexis set nobi Principis ofitio su autor diomedes Catrafa, ympreso año demil seiscientos y sesentay ocho.

- Otro enquarto silloga variorun tratatun, caroli Regi anglis, galiz et yberni.

- Un Libro enquarto enytaliano su titulo Comentario dela Guerra suzedida en Alemania, en tpo del rey Gustabo adolfo desuecia su autor el conde Mayolino Visaccioni ympreso año de mil setecientos treintay seis. 
-Otro en quarto su titulo Razon y merito dela Magd del Sr dn carlos deBorbon Rey deNapoles para obtener dela santa sede apostolica lapresentacion, o nominacion del episcopato,Abadia, y beneficio Consistorial desus estados deItalia.

-Otro en octavo su titulo La Italia Regnante, con nueva descripcion detodo elestado presente del Principado, y republica deItalia ympreso año demil seiscientos sesentay quatro.

-Otro Libro en octavo en castellano, manuscrito su titluo la RI fabrica deoja delata escrito año de quarentay seis.

-Otro en octavo, yntitulado vida desn Luis Rey defrancia ynpreso año demil seiscientos cinquentay cinco.

-Otro en octavo su titulo vida desantiago por el Padre fr Ignacio Catoira dominico ympreso año demil setecientos quarentay uno.

-Otro en octavo, constituciones, delaCompañía de Jesus ynpreso año demil seiscientos y seis.

-Otro en octavo, su titulo ynfancia Ilustrada yniñez instruida entodo genero devirtudes xptianas, politicas ymorales que conducen ala santa educacion y crianza delos niños su autor Sr dnJuan Elias Gomez de theran, obispo de Orihuela, ympreso año demil seteytos quarenta y uno.

-Otros doze en octavo su autor el dho sr obispo de Horibuela ympreso año desetecientos treinta y ocho, asistencia delamisa y dibinos oficios.

-Otro en octavo sutitulo directorio Catholico, ympreso año desetecientos veinte y tres.

-Otros dos tomos en octavo su titulo españa enlaSta Biblia exposicion ystorial delos testos tocantes a españoles su autor el Padre Pablo yanes cisterciense ynpreso año demil setecientos treinta y cinco.

-Un libro enquarto su titulo Monacato Geronímano con algunos reparos sre un libro intitulado examen castellano apendize animadversion concisa ycompenciosa respuesta al Padre Mro fr Manuel desn Antonio su autor el Padre fr Joseph Gonzalez Geronimo.

-Otro enquarto Contituciones, y ordenanzas delos seminarios deorihuela y casas demisericordia su autor dnJuan Elias Gomez detheran obispo dedha Ciudad, ympreso, año demil setecientos quarenta y quatro.

-Otro en quarto su titulo Hospital RI decorte su autor dn franco Bermudez Pedraza ympreso año demil seiscientos quarentay cinco.

-Otro enquarto su titulo año santo dentro y fuera deRoma su autor el Padre fr Juan Raulin Agustino.

-Otros cinco tomos enquarto, Historia del Pueblo deDios traducido al español, por el Pe Antonio de Espinosa Jesuita.

-Otro enquarto, Memorial theologico delaxa y nezesidad dela sagrada difinicion del misterio dela Inmaculada Concepcion de Maria ssma. su autor dn Ignacio Lopez Moreno, ympreso año demil setecientos treintay quatro.

-Otro enquarto su titulo Reformacion xptiana, asi delpecador como del birtuoso. su autor el Padre franco Castro. Jesuita, ympreso año demil setecientos veintey nuebe.

-Otro en quarto Compendio de las tres leyes natural escrita y ebengelica dn franco Perez de Prado y cuesta.

-Otro enquarto vida exemplar y cirtudes heroicas del Venerable Padre dn Geronimo Albarrategui delorn desn Cayetano, su autor dn diego de torres villarroel.

-Otro enquarto breberelayn delaMuerte viday virtudes del venerable cavallero dn Miguel Mañara, su autor el Padre Juan de Cardenas Jesuita, ympreso, año demil seiscientos setentaynueve.

-Otro enquarto su titulo anfiteatro sagrado sre la Canonizacion desn Luis Gonzaga y san estanislao, su autor dn Pedro clemente Valdes.

-Otro enquarto su titulo Memorial dado por dn Juan chumazeroy Carrillo y dn fr domingo Pimentel, obispo de Cordova, a lasantidad deUrbano octavo en nre de Vsr Rey dn Phelipe Quarto, sobre los eszesos que se cometen en Roma, contra los naturales destos reynos ynpreso año demil seiscientos treintay tres.

-Un Libro en octavo en latín razon einstituto delos estudios dela Compañía de Jesus.

-Otro en octavo ynstituciones dela Compañía de Jesus.

-Un Libro enquarto su titulo carta Pastoral de Vrs Velasco.Arzobispo detoledo.

-Otro enquarto su titulo Polianteo obra quecontiene cien sermones conpuesto devarias autoridades dela escriptura.

-Otro en quarto Zeremonial quecontiene laRitus dela eleccion Romana delPontificado deGregorio Papa decimo quinto. 
-Otro en octavo su titulo vida del duque de Riperda traducido delfranzes al castellano por Monsr le Margre ympreso año demil setecientos y quarenta.

-Otro enoctavo su titulo Guerra deGranada hecha por el Rey deespaña dn Phelipe segundo su autor dn Diego deMendoza ympreso año demil setecientos y treinta.

-Un Libro enquarto su titulo Historia General dela America septentrional su autor Lorenzo Boturini, ympreso año demil setecientos treintay seis.

-Otro enquarto su titulo viaje Rl del rey nro Sr dn Phelipe Quinto su autor dn Pablo Montes encio, ympreso año de mil setecientos veinte y uno, digo doze.

-Otros siete tomos enquarto su titulo diario delos literatos deespaña Compuesto por dn franco Huerta, dnJuan de solafranca y dn Leopoldo Puig ympreso año demil setecientos treinta y siete.

-Otro enquarto derecho deespaña almilanes ympreso año demil setecientos quarentay dos, traducido al castellano, por dn Miguel Joseph deAoiz.

-Un Libro enquarto derecho deespaña alos estados hereditarios dela Casa deAustria ympreso año demil setecientos treintay dos.

-Un Librito en octavo en latín sutitulo Grotius de Maria Libero, ympreso año demil setecientos treintay tres.

-Otro enquarto su titulo frax cronologico Adonifenani Historiam su autor el Pe Juan dominico Musancio Jesuita ympreso año de mil setecientos y uno.

-Otro enquarto su titulo seldini dedominio maris.

-Un tomo en octavo su titulo Istoria secreta deHenrrique quarto Rey de Castilla ympreso año de mil seiscientos y nobentay seis.

-Otro en octavo sutitulo Genealogia delos Grandes de españa su autor Jorge Hermont ynpreso año demil setecientos y siete.

-Un Librito en octavo en ytaliano sumario Istorico que contiene elestado del mundo.

-Otro en octavo su titulo la rebolucion deNapoles, suautor Alejandro Guirafi ympreso año demil setecientos diez yocho.

-Otro en octavo su titulo floresta yluminada dela Ciud deBenecia ympreso año demil setecientos y treinta.

-Un Libro en octavo su titulo compendio cronologico delaHistoria deeste siglo. su autor dn salbador don Jph Mañer ympreso año demil setecientos quarentay uno.

-Otro en octavo su titulo obras deCayo xpto sulustio por Manuel Surio ympreso año demilseiscientos y quince.

-Un Libro enquarto su titulo Imperio dela china y cultura evangelica en el porlos religiosos delaCompañía de Jesus su autor el Padre Albaro semmedi Jesuita ynpreso año de mil seiscientos quarentay dos. -Otros dos en quarto su titulo el orinoco Ilustrado ydefendido Historia natural cibil y Geogrefica deste gran Rio Goberno uso y costumbres delos Indios su autor el Padre Joseph Gumilla dela Compañia de Jesus año demil setecientos quarentay cinco.

-Otro en quarto su titulo adbertencias Historicas sobre las obras dealgunos doctos escriptores modernos su autor dn Luis desalazar y Cardenas, ympreso año demil seiscientos ochenta y ocho.

-Otros dos tomos, primero, segundo y tercero en quarto. su titulo Historia Romana traducidos delfranzes al español por el Padre Mro Juan deAller, clerigo menor ympreso año demil setecientos treinta y cinco.

-Otros dos tomos enquarto su titulo Comentarios dela Guerra deespaña eystoria desu Rey dn Phe Quinto el animoso, desde principio de su reinado asta lapaz gral delaño demil setecientos veinte ycinco su autor el Marques desn Phelipe.

-Otros dos tomos enquarto, heras, y fechas deespaña, su autor el Pe Mro fr Pablo Jañes Iterciense, ympreso año demil setecientos treintay dos.

-Otro enquarto su titulo Diazcano, Vindicado apologia dela notoria lealtad dedon franco diaz Cano. Su autro el Padre Pedro Cano, dominico, Impreso año demil setecientos y quarenta.

-Un Libro en quarto en latín su titulo rexis set nobi Principis ofitio su autor diomedes Catrafa, ympreso año demil seiscientos y sesentay ocho.

-Otro enquarto silloga variorun tratatun, caroli Regi anglis, galiz et yberni.

-Un Libro enquarto enytaliano su titulo Comentario dela Guerra suzedida en Alemania, en tpo del rey Gustabo adolfo desuecia su autor el conde Mayolino Visaccioni ympreso año de mil setecientos treintay seis. 
-Otro en quarto su titulo Razon y merito dela Magd del Sr dn carlos deBorbon Rey deNapoles para obtener dela santa sede apostolica lapresentacion, o nominacion del episcopato, Abadia, y beneficio Consistorial desus estados deItalia.

-Otro en octavo su titulo La Italia Regnante, con nueva descripcion detodo elestado presente del Principado, y republica deItalia ympreso año demil seiscientos sesentay quatro.

-Otro Libro en octavo en castellano, manuscrito su titluo la RI fabrica deoja delata escrito año de quarentay seis.

-Otro en octavo, yntitulado vida desn Luis Rey defrancia ynpreso año demil seiscientos cinquentay cinco.

-Otro en octavo su titulo vida desantiago por el Padre fr Ignacio Catoira dominico ympreso año demil setecientos quarentay uno.

-Otro en octavo, constituciones, delaCompañía de Jesus ynpreso año demil seiscientos y seis.

-Otro en octavo, su titulo ynfancia Ilustrada yniñez instruida entodo genero devirtudes xptianas, politicas ymorales que conducen ala santa educacion y crianza delos niños su autor Sr dnJuan Elias Gomez de theran, obispo de Orihuela, ympreso año demil seteytos quarenta y uno.

-Otros doze en octavo su autor el dho sr obispo de Horibuela ympreso año desetecientos treinta y ocho, asistencia delamisa y dibinos oficios.

-Otro en octavo sutitulo directorio Catholico, ympreso año desetecientos veinte y tres.

-Otros dos tomos en octavo su titulo españa enlaSta Biblia exposicion ystorial delos testos tocantes a españoles su autor el Padre Pablo yanes cisterciense ynpreso año demil setecientos treinta y cinco.

-Un libro enquarto su titulo Monacato Geronímano con algunos reparos sre un libro intitulado examen castellano apendize animadversion concisa ycompenciosa respuesta al Padre Mro fr Manuel desn Antonio su autor el Padre fr Joseph Gonzalez Geronimo.

-Otro enquarto Contituciones, y ordenanzas delos seminarios deorihuela y casas demisericordia su autor dnJuan Elias Gomez detheran obispo dedha Ciudad, ympreso, año demil setecientos quarenta y quatro.

-Otro en quarto su titulo Hospital Rl decorte su autor dn franco Bermudez Pedraza ympreso año demil seiscientos quarentay cinco.

-Otro enquarto su titulo año santo dentro y fuera deRoma su autor el Padre fr Juan Raulin Agustino.

-Otros cinco tomos enquarto, Historia del Pueblo deDios traducido al español, por el Pe Antonio de Espinosa Jesuita.

-Otro enquarto, Memorial theologico delaxa y nezesidad dela sagrada difinicion del misterio dela Inmaculada Concepcion de Maria ssma. su autor dn Ignacio Lopez Moreno, ympreso año demil setecientos treintay quatro.

-Otro enquarto su titulo Reformacion xptiana, asi delpecador como del birtuoso. su autor el Padre franco Castro. Jesuita, ympreso año demil setecientos veintey nuebe.

-Otro en quarto Compendio de las tres leyes natural escrita y ebengelica dn franco Perez de Prado y cuesta.

-Otro enquarto vida exemplar y cirtudes heroicas del Venerable Padre dn Geronimo Albarrategui delorn desn Cayetano, su autor dn diego de torres villarroel.

-Otro enquarto breberelayn delaMuerte viday virtudes del venerable cavallero dn Miguel Mañara, su autor el Padre Juan de Cardenas Jesuita, ympreso, año demil seiscientos setentaynueve.

-Otro enquarto su titulo anfiteatro sagrado sre la Canonizacion desn Luis Gonzaga y san estanislao, su autor dn Pedro clemente Valdes.

-Otro enquarto su titulo Memorial dado por dn Juan chumazeroy Carrillo y dn fr domingo Pimentel, obispo de Cordova, a lasantidad deUrbano octavo en nre de Vsr Rey dn Phelipe Quarto, sobre los eszesos que se cometen en Roma, contra los naturales destos reynos ynpreso año demil seiscientos treintay tres.

-Un Libro en octavo en latín razon einstituto delos estudios dela Compañía de Jesus.

-Otro en octavo ynstituciones dela Compañía de Jesus.

-Un Libro enquarto su titulo carta Pastoral de Vrs Velasco.Arzobispo detoledo.

-Otro enquarto su titulo Polianteo obra quecontiene cien sermones conpuesto devarias autoridades dela escriptura.

-Otro en quarto Zeremonial quecontiene laRitus dela eleccion Romana delPontificado deGregorio Papa decimo quinto. 
LA BIBLIOTECA DE AGUSTÍN PABLO DE ORDEÑANA

-Otro en quarto decretos del sacro santo Concilio tridentino, su autor el Padre fr Pedro Marcilla Venedictin.

-Otro enquarto su titulo Peripates combertidos entreinta salmos su autor Alejandro Farnacio Cardenal.

-Otro enquarto salmos deDavid y otros Vatricinios traducido de lengua ebrea ala latina por Venedicto Arias Montano.

-Seis Libros en octavo en ytaliano obras del Padre Paulo del orn del sicruo que trata del entredho dela santidad del Papa Paulo quinto.

-Otro en octavo ystoria dela pasion ymuerte denro Sr su autor Filogramo Ragueral.

- Un Libro en octavo en Castellano el Peregrino ensu patria su autor Lope devega Carpio.

-Otros dos en octavo la dorotea acion en prosa su autor dho Lope deVega.

-Otro en octavo vida de migl deZerbantes su autor dn Gregorio Manans.

-Otro en octavo su titulo, trajedia decina de Pedro Cornelio traducido delfranzes.

-Un Libro enquarto su titulo dicionario Castellano y latín, su autor Juan Alfonso fontecha.

- Otro enquarto su titulo heroticas o amatorias conpuestas por dn esteban Manuel devillegas.

-Otro en quarto endefensa deun memorial delas mugeres deespaña suautor dn Andres Gonzalo.

-Otros dos enquarto su titulo Carta del Mro de niños su autor dn Gabriel Albarez detoledo.

-Otro en quarto Jornada delos coches de Madrid Alcala.

-Otro enquarto obras dedn Luis deulloa ympreso eño demil seiscientos setenta y quatro.

-Otro en quarto en castellano obras de Jerardo Lobo.

-Otro en quarto el templo de lafama con ynstruciones politicas y morales, su autor fr Andres ferrer dominico.

-Otro en quarto, obras postumas dedn Gabriel Albarez de toledo, su autor dn diego de torres.

-Otro enquarto, obras satiricas dedn franco deQuebedo manuscrito.

-Otro enquarto el polifemo dedn Luis de Gongora, comentado por dn Garcia desalzedo.

-Otro enquarto Palacio de Momo apologia Jocoseria pr la Istoria delalglesia, y del mundo, y por su autor dn Gabriel Albarez detoledo, escrita la apologia por Encio Anastasio, Heliopolitano.

-Otro en quarto citara de Apolo varias poesias dibinas y humanas que escribio dn Agustin desalazar.

- Otro enquarto la Galatea y añadido el viaje del Parnaso su autor Miguel de Zerbantes obras poeticas.

-Otro en quarto obras liricas Comicas, dibinas y humanas con lazelestial ambrosia dela admirable poema sacro de María santisima su autor dn Antonio Hurtado, // Otro en quarto Horlando furioso deludobico Aliosto traducido del toscano por dn Geronimo deurrea.

-Un Libro en octavo en Latin Panteon o fabulosa Istoria delos dioses su autor el Padre franco Pomei Jesuita.

-Otro en octavo, fastos de publio obidio nason.

-Otro en octavo comedias de tarencio ympreso en latín eytaliano.

-Otro en octavo manuscrito Juegos pueriles su autor Julian Navarro.

-Un Libro enquarto disposiciones filosoficas ymedicas sobre los Libros deAristoteles suautor Juan Gutierrez deGodoy.

-Un Libro en octavo Gramatica Castellana su autor dn Venito Gomez Gayoso.

-Otro en octavo explicación de las reglas de Generos y de preteritos como se enseñan enla Compañía de Jesus su autor thomas Garcia deolarte.

-Otro en octavo epitome dela eloquencia española su autor dn franco Joseph ortega.

-Otro en octavo ortographía española su autor la Rl Academia española.

-Otro en octavo las Catorce Questiones deAlfonso tostado.

-Otros tres tomos en octavo el arte explicado y gramatico perfecto su autor dn Marcos marques.

-Otros tres tomos en octavo, ciencia heroica sobre las leyes heraldicas del blason su autor dnJoseph Abiles.

-Otro en octavo reglas de ortographia en la lengua castellana su autor Antonio Nebrija.

-Otro en octavo declamaciones Castellanas autor dn Gabriel Vocartei.

-Otro en octavo uso del Globo y del Mapa con las figuras nezesarias su autor dn Luis de Losada.

-Otro en octavo el mexor Principe trajano augusto su filosofia politica moral. suautor dn franco varreda.

-Otro en octavo thesoro dela memoria y del entendimto y arte breve para todas sabidurias, su autor Miguel deBargas.

-Otro en octavo La orn delos francos Macones y el secreto demoises rebelado ynpreso año demil setecientos quarentay cinco.

-Otro en octavo Retarto al bibo del natural delfortuna su autor Antonio Perez. 
-Un Libro en quarto el secreto en diez y seis discursos que comprenden atodo genero deministros su autor dn Bernardo Gonzalez.

-Otro en quarto Calepino de Sales.

-Otro en quarto refranes Castellanos y latinos su autor dn Geronimo Martin Zejudo.

-Otro enquarto bocabulario delas dos lenguas toscanay Castellana su autor dn xptobal delas Casas.

-Un Libro en octavo en Latín su titulo Janonicio edítreo Pinacbthica que trata devarios eylustres varones quemurieron en su tiempo.

-Otro en octavo, ythenerario de Antonio Agustin sobre dibersos manuscritos einpresos, cobdicas, enmendados de Geronimo Zurita.

-Otro en octavo Mor vodis Glli Poete que trata depiedras preciosas.

-Un Libro en octavo primeros rudimentos dela Gramatica suautor Antonio Molín.

-Otro en octavo las ocho partes dela oracion Gramatical su autor el Padre Bartome Bravo Jesuita.

-Otro en octavo Platon sobre varias lecciones y notas de dn Cambino, y otras difiniciones deldicho, Con otors quatro varones.

-Otro en octavo, fabulas de fedro, Augusto Liberto.

-Otro en octavo, enfranzes, memorias para la Histroria delas ciencias.

-Otro en octavo, en Italiano, ortographia toscana, su autor Anjel Gaboso.

-Otro en octavo, el secretario principiante eyntruido su autor dn Isidro Mardi.

-Otro en octavo llabe deoro dela Gramatica suautor dnThiberio de Luca.

-Otro en octavo Gramatica dela Lengua tudeica su autor Mathias Chresmair.

-Otro en octavo Bocabulatio ytaliano.

-Un Libro en octavo en castellano, tratado delberdadero merito del Hombre Considerado encada hedad y en cada Condicion, suautor dn franco Elbria.

-Otro enquarto tablas deRedución, su autor dn Phelipe Medrano.

-Un Manuscrito en quarto disrio dela Campaña que hizo elexercito del Rey año dequarentay tres.

-Un Memorial enquarto del Colegio deVoticarios de esta Corte.

-Otro enquarto Seneca inpugnado suautor dn Alonso Muñoz deCastro.

-Otro enquarto Comentario deSeneca delsabio en la pobreza, su autor dn Juan Vaños deVelasco.

-Otro enquarto encastellano y latin, desertacion segunda medalla dela Colonia de tarragona que representa atiberio augusto, a Julia augusta, hixa deZesar augusto, muger detiberio y Adriano Zesar su hixo, su autor el Padre Alexandro Xavier Pañiel Jesuita.

-Otro enquarto Compendio dela nobilisima fundacion y Privilegios delcolegio mayor desn clemente delos españoles deBolonia su autor dn Salbador silbestre Velasco Presbitero.

-Otros dos tomos enquarto cannochiale aristotelico o anteojo delarga vista ydea dela Agudera eynjeniosa locuyn su autor fr Miguel deSequeiros Agustino.

-Otro en quarto ocaso delas formas Aristotelicas quepretendio ylustrar a la luz de laRazon dnJuan Martín de Lesaca obra postuma de dn Diego Matheo Zapata.

-Otro en quarto, filosofía moral deribada de alta fuente de Aristoteles su autor dn Gomez dela Rochay Figueroa.

-Otro en quarto Logica Moderna, o arte de allar la berdad, en castellano y perfecionar laRazon, su autor Andres Piquer.

-Otro enquarto Filosofía antigua, poetica, su autor Dn Alonso Lopez Pinciano Medico Zesareo.

-Otro enquarto el embajador su autor dnJuan Antonio deVeray Zuñiga.

-Otro enquarto el Ayo y Mro dePrincipes Seneca ensu vida, su autor dn Juan Vaños deVelasco.

-Otro en quarto Anneo seneca ylustrado enblasones políticos ymorales su autor dn Juan Vaños Velasco.

-Otro enquarto adbertencias paraReyes Principes y enbajadores su autor dn christobal deBenabente y benabides.

-Un Libro enquarto en Latín medulla filosofie protenalie, curio, yntres partes distributa su autor fr Joseph del espiritusto trinitario descalzo.

-Otro enquarto Hipotiphnis arcuin Pallatiorum librorum piramidum obeliscorum cipporum midenium fomti ummonumenciarum et epitaphorum ab ylustre extruo viro enrico Rancobio.

-Otro enquarto diabogas de recta pronunpctiatione lingue su autor phelipe sudneye.

-Otro en quarto su titulo, viridaruin moralis, philosoph su autor Gregorio Mutingo.

-Un Libro en Portugues enquarto apuntamentos pa la educayn dela Jubentud, su autor Martin de Mendoza.

-Un Impreso vida del Pe fr Alonso deOrozco religioso Agustino su autor fr Man de Quevedo. 


\section{LA BIBLIOTECA DE AGUSTÍN PABLO DE ORDEÑANA}

-Un Libro en octavo tratado util para Confesar su autor fray Antonio de Medina Cartujo.

-Otro enfolio Informe endro que la Compañía del Real Asiento de la Gran Bretaña establecida para la ynstrucion de esclacos negros en las Indias, debe declararse libre y de la paga de los Reales derechos, escrito por dn Gerardo Moro Hirlandes.

-Otro en folio, ynstruciones antiguas y modernas del santo oficio dela Inquisición, puestas por Abezedarios su autor Gaspar Isidro Arguello.

-Otro enquarto su titulo compendio delas tres gracias dela sta cruzada subsidio su autor Alonso Perez de Lara.

-Otro enquarto reglas de la poesia engeneral y desus principales especies su autor dn Ignacio Luzan. -Un Lagejito devarios suzesos en latín de lavida desn Bernardo.

-Un Libro enfolio testamento del señor Albornoz Arzobispo detoledo.

-Dos tomos sin enquadernar enfranzes dicionario militar o Reglas alphabeticas detodos los terminos propios del arte militar.

-Otro sin enquadernar su titulo letre deMadame la Marquise de M.

-Otro en quarto edicto deel republica de Genoba.

-Otros dos tomos enfranzes el Argoz dela europa suautor M. G. de Ju.

-Otros tres tomos en octavo su titulo Actos memorias y otras piezas autenticas conzernientes a la paz deutrech.

-Otro en octavo las Letras y memorias escritas por Monsieur el Abad de Montegon conzernientes alas negociaciones deque estubo encargado.

-Un Quaderno ynpreso en ytaliano, tratado del del alma vestra su autor el Padre Ignacio Pardies.

-Otro en octavo su titulo dhos deJuan deBotero.

-Otro en octavo el secretario principiante einstruido su autor dn Isidro Mardi.

-Otro enquarto laPlaza universal detoda laprofesion del mundo su autor thomas Garzoni.

-Otro enfolio, memorias Historicas de la Guerra dela Casa deAustria alaReal Casa deBorbon su autor Agustino omicalia.

-Otro enpergamino enquarto salazar origen dela renta del servicio de Montazgo.

-Otro viaje del Rey dn Carlos segundo a Aragon.

-Otro Columnensium Procerum.

-Otro enfolio, viaje del Rey altalia.

-Iden doscientos y nobentay seis Libros sin enquadernar y Librillos manuscritos sobre el Gobierno defrancia y dos Mazos de Guias deforasteros deespaña y francia.

Y habiendose concluido el referido Imvrio se firmó por el Vsr dnJph Aparicio, y el citado dn Benito Hernaez, quien se entregó delos vienes y alajas que comprende, para responder y dar salida deellos, siempre quese le mande de que zertifico. Madrid y Julio treintay uno demil seteytos cinquentay quatro.

D Josepb de Aparicio

Benito Hernaez

Don Josepb Ant. de Amaya 